\title{
Integrated Process Chain for Aerostructural Wing Optimization and Application to an NLF Forward Swept Composite Wing
}

\author{
Tobias Wunderlich and Lars Reimer
}

\begin{abstract}
This contribution introduces an integrated process chain for aerostructural wing optimization based on high fidelity simulation methods. The architecture of this process chain enables two of the most promising future technologies in commercial aircraft design in the context of multidisciplinary design optimization (MDO). These technologies are natural laminar flow (NLF) and aeroelastic tailoring using carbon fiber reinforced plastics (CFRP). With this new approach the application of MDO to an NLF forward swept composite wing will be possible.

The main feature of the process chain is the hierarchical decomposition of the optimization problem into two levels. On the highest level the wing planform including twist and airfoil thickness distributions as well as the orthotropy direction of the composite structure will be optimized. The lower optimization level includes the wing box sizing for essential load cases considering the static aeroelastic deformations. Additionally, the airfoil shapes are transferred from a given NLF wing design. The natural laminar flow is considered by prescribing laminar-turbulent transition locations.

Results of wing design studies and a wing optimization using the process chain are presented for a forward swept wing aircraft configuration. The wing optimization with 12 design parameters shows a fuel burn reduction in the order of $9 \%$ for the design mission.
\end{abstract}

T. Wunderlich

German Aerospace Center,

Institute of Aerodynamics and Flow Technology,

Lilienthalplatz 7, 38108 Braunschweig, Germany

e-mail: tobias. wunderlich@dlr. de

L. Reimer

German Aerospace Center,

Institute of Aerodynamics and Flow Technology,

Lilienthalplatz 7, 38108 Braunschweig, Germany

e-mail: lars.reimer@dlr.de 


\section{Introduction}

The environmental impact of aviation increases with the rapid growth of air travel and transport. For this reason efficiency of future air transport must be improved significantly. The research and development of future transport aircraft have to meet this challenge. A Strategic Research Agenda has been developed by the Advisory Council for Aeronautics Research in Europe (ACARE). The goals of the European aeronautical research have been formulated in this research agenda and have been published in the "Vision 2020" [1], [2] and the "Flightpath 2050" [3]. In order to protect the environment and to preserve the energy supply a $50 \%$ reduction of the $\mathrm{CO}_{2}$ emissions per passenger kilometer has been requested for the year 2020 based on the values of the year 2000. The airframe contribution should be in the order of $20 \%$ to $25 \%$ in terms of fuel consumption reduction.

To achieve these challenging goals the development timescales for new technologies including new aircraft concepts have to be reduced significantly. For the assessment of an aircraft configuration it is essential to consider all relevant disciplines and their interactions on overall aircraft level. The consideration of new technologies and aircraft concepts requires a physics based approach because no statistics are available anymore. In order to represent the physics in a realistic manner, accurate simulation tools have to be applied. With increasing accuracy of the disciplinary simulations the geometrical description has to be improved, too. This inherently leads to increased computational costs. The development of accurate and fast numerical simulation and optimization processes is getting more and more important. In this context new capabilities in the areas of process architecture, program interfaces, parallelization and the usage of high performance computing (HPC) are required.

The combination of increasing computer resources and advanced numerical simulation tools enables the accurate prediction of flight performance of a transport aircraft configuration [4]. The use of these high fidelity simulation programs for aerodynamic design and optimization has been demonstrated in the MEGADESIGN project (Kroll et al. [5], [6], [7], [8] and Gauger [9]).

State of the art high fidelity analysis methods already routinely include fluidstructure coupling of the aircraft wing for a given structural model. The consideration of fluid-structure interactions gets more important for the accurate performance and load prediction of highly flexible wings.

Improvements in automation and coupling of accurate simulation methods in combination with advances in numerical optimization strategies lead to the emergence of MDO based on high fidelity methods.

Multidisciplinary wing optimizations for realistic aircraft configurations under consideration of static aeroelasticity have been shown for example by Piperni et al. [10] for a large business jet and by Chiba et al. [11] for a regional jet.

The challenge in using MDO based on highly accurate methods is the large number of design parameters and the increased computing effort. To overcome this issue, the adjoint method enables the efficient calculation of the flow variable gradients as a function of the design parameters for gradient based optimizations. The adjoint 
method was used by Jameson, Leoviriyakit and Shankaran [12] for a gradient based multidisciplinary wing optimization with fluid-structure coupling. Up-to-date applications of the adjoint approach for multidisciplinary wing optimization have been shown in the publications of Kenway and Martins [13], Kenway, Kennedy and Martins [14] and Liem, Kenway and Martins [15]. These publications show that the gradient based optimization using the adjoint approach is an adequate method for multidisciplinary wing optimization with high fidelity simulation programs and a large number of design parameters.

In this contribution an alternative MDO approach is introduced for cases in which gradients cannot be computed efficiently for all relevant disciplines. This applies particularly to cases which involve laminar-turbulent transition prescription and structural sizing of composite structures using proprietary codes. Furthermore, a certain degree of flexibility in the process architecture and optimization strategy is desired. Especially the option to use optimization strategies seeking for the global optimum is important.

The application of MDO to new aircraft concepts and technologies using high fidelity methods is very promising. By using MDO an accurate comparison between optimal solutions based on conventional and new technologies will be possible. This facilitates an adequate assessment of new concepts and technologies on the one hand. On the other hand, this requires the availability of physics-based simulation models and efficient programs with adequate interfaces.

To improve the aerodynamic efficiency of commercial aircraft, modern technologies for drag reduction have to be applied. A short overview of aerodynamic wing design and corresponding technologies is given for example by Horstmann and Streit [16]. One of the most promising drag reduction technologies is laminar flow control (LFC). The potential of this technology for drag reduction of commercial aircraft has been described by Schrauf [17] and Green [18] for example.

In 1979, Boeing already investigated the benefit of NLF on large transport aircraft [19]. This study shows that the aircraft having an NLF wing design was not competitive against a turbulent wing design taking the top level aircraft requirements as a basis for comparison. In the DLR project LamAiR [20], however, the concept of forward sweep for laminar wings as proposed by Redeker and Wichmann [21] shows significant potential for efficiency improvements. In this project an aerostructural wing design of a forward swept wing having NLF and a composite structure including aeroelastic tailoring has been performed. The results have been published by Kruse et al. [22].

The work on aeroelastic tailoring is summarized by Shirk et al. [23]. In this publication aeroelastic tailoring is described as

...embodiment of directional stiffness into an aircraft structural design to control aeroelastic deformation, static or dynamic, in such a fashion as to affect the aerodynamic and structural performance of that aircraft in a beneficial way.

Additionally, the advantages of composite materials on forward swept wings are explained. Tailoring the primary stiffness direction relative to the structural reference axis introduces a bend-twist-coupling that can be used to counteract the susceptibility of forward swept wings to static divergence. Dähne et al. [24] investigated the 
influence of aeroelastically tailored composites on structural mass. In this study an automated structural sizing process has been applied with the simplification that the aerodynamic loads remained fixed.

In striving for the capability to assess new wing technologies by development and application of an integrated process chain has been one of the main topics in DLR's contribution to the LuFo IV joint research project AeroStruct. In the scope of the project an integrated process chain for aerostructural wing optimization considering new wing technologies such as forward sweep, NLF, composite materials and aeroelastic tailoring have been developed. In the setup of the process chain it was made sure that the aerodynamic loads of all load cases entering the structural sizing always result from fluid-structure coupled simulations. Wunderlich [25] showed that this has crucial influence on the aerostructural wing optimization results.

\section{Process Chain for Aerostructural Wing Optimization}

An integrated process chain for aerostructural wing optimization based on high fidelity simulation methods has been developed. The developed process chain can be characterized by the following items:

- Usage of a central file format for parametric aircraft description,

- Automated grid generation for aerodynamic simulation,

- Automated structural model generation for structural simulation,

- Parallel static aeroelastic analysis for an arbitrary number of load cases,

- Structural wing box sizing for composite structures,

- Consideration of NLF by prescribing laminar-turbulent transition locations,

- Applicability for large geometrical changes and global optimization strategy.

The selected MDO architecture falls in the category of MDF-optimization (MultiDisciplinary Feasible) and can be described as ASO (Asymmetric Subspace Optimization) according to Martins and Lambe [26]. In the MDF architecture a full multidisciplinary analysis (MDA) is performed for each optimization iteration. This means that the investigated design fulfills all constraints in each optimization step and hence is called a feasible design.

In Fig. 1 the process chain is illustrated with an XDSM-diagram (Extended Design Structure Matrix) [27]. This type of diagram combines the information of process flow between computational components with the information of data dependency. Each component in the diagram takes input data from the vertical direction and provides output data from the horizontal direction. Input and output data are marked by parallelograms. Thick gray lines show the data flow. Thin black arrows indicate the process flow, and a numbering system is used to define the order in which the components are executed.

The starting point for an aerostructural wing optimization is normally a detailed geometrical model of a given reference aircraft configuration. From this nonparametric model a fully parametric description of the aircraft using the Common 


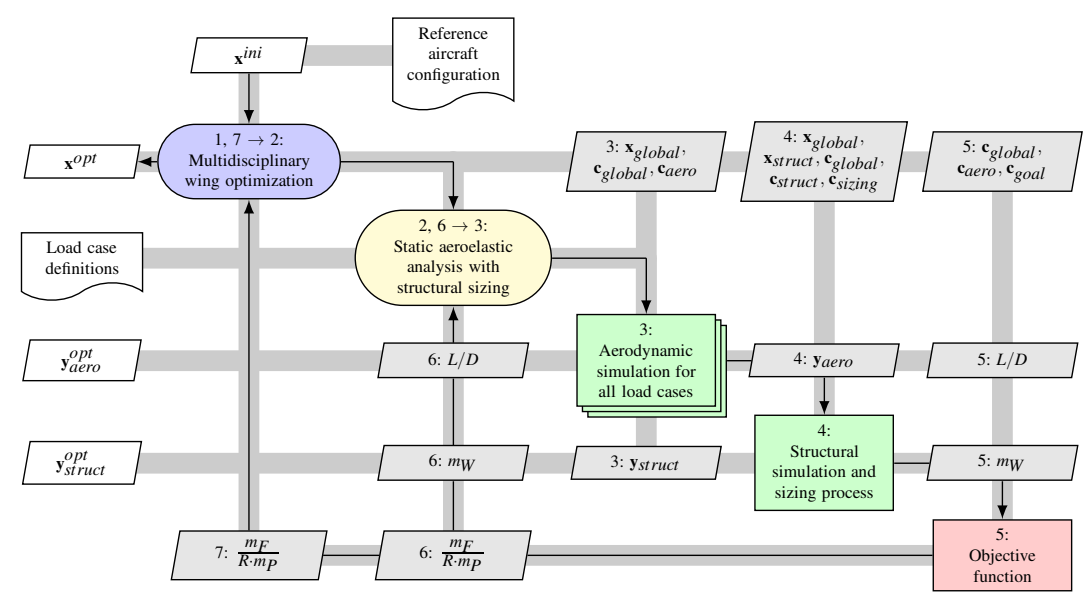

Fig. 1 Flow chart of the process chain for aerostructural wing optimization.

Parametric Aircraft Configuration Schema (CPACS) has to be generated manually or with a program in an automated way. Furthermore, the initial vector of design parameters $\mathbf{x}^{i n i}$ is determined by the reference aircraft configuration. The load case definitions for the structural sizing have to be identified and stored in the CPACS dataset.

All disciplinary simulation programs in the process chain provide interfaces to this central hierarchical and human readable file format. In Sect. 2.2 the parametric model and the CPACS dataset are described in more detail.

The driver component controls the optimization iteration and is represented in Fig. 1 by a blue rounded rectangle. Based upon a design parameter variation and a following transfer to the CPACS dataset the disciplinary models are built or updated automatically. Thereby, the vector of design parameters $\mathbf{x}$ describes the wing planform including twist and airfoil thickness distributions and the orthotropy direction of the composite structure.

The static aeroelastic analysis is then run in parallel for all load cases including the design point under cruise flight conditions. In the actual implementation, the process chain is limited to steady state maneuver load cases and only the wingfuselage configuration is analysed within the high-fidelity simulation process.

For each load case the surface pressure distribution and aerodynamic coefficients of the wing are determined by solving the Reynolds-averaged Navier-Stokes equations (RANS) within a numerical flow simulation. Elastic characteristics of the wing and its internal loads are determined using the finite element method (FEM). Subsequently, the wing mass is deduced by processing these internal loads. The interactions between the aerodynamic forces and the structural deformations of the elastic wing are taken into account in the static aeroelastic analysis. The fluid-structure interaction belongs to the category of loosely coupled analysis as described in [28] and [29]. Thereby, the fluid-structure coupling loop stops when the values for the lift- 
to-drag ratio, wing mass and fuel consumption are converged. The fluid-structure coupling loop is shown in Fig. 1 by a yellow rounded rectangle.

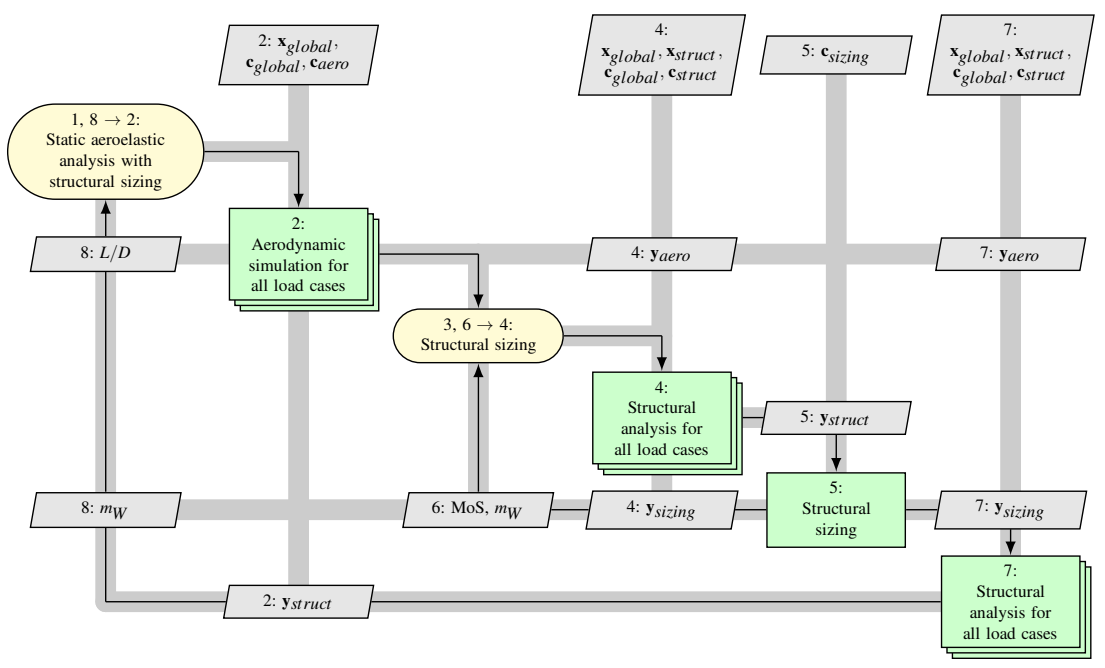

Fig. 2 Flow chart of the parallel static aeroelastic analysis including structural sizing.

Fig. 2 gives more insight into the parallel static aeroelastic analysis including structural sizing. Within the parallel static aeroelastic analysis the wing box structure is sized and the bending and torsional stiffness of the wing converge in the fluid-structure coupling loop. Thereby, the structural sizing forms an inner loop to fulfill the structural constraints in terms of failure criteria and converge the margins of safety (MoS) and the wing mass $m_{W}$ for a fixed aerodynamic load.

The main results of this parallel analysis are the wing mass $m_{W}$ and the deformed wing shape for the design point under cruise flight conditions, which is normally called "1 $\mathrm{g}$-flight shape". Based on this $1 \mathrm{~g}$-flight shape the aerodynamic performance in terms of lift-to-drag ratio $L / D$ is determined.

The last step in the process chain is the evaluation of the objective function $f$ for the multidisciplinary assessment of the wing design. The optimization algorithm then calculates a new set of values for the design parameters based on the value of the objective function. After the optimization run has been finished the optimized vector of design parameters $\mathbf{x}^{o p t}$ represents the main result of the process chain for the corresponding optimization problem. 


\subsection{Flight Mission and Objective Function}

For the evaluation of the objective function a simplified model of the flight mission has been used. This model is described in the textbook by Raymer [30] and is often used for preliminary aircraft design.

In this work, the flight mission consist of five segments. Table 1 gives an overview of these flight mission segments and the corresponding aircraft mass fractions. With the exception of the cruise flight segment the values for the aircraft mass fractions have to be prescribed depending on the optimization problem.

\begin{tabular}{clc}
\hline Segment number & Mission segment & Aircraft mass fraction \\
\hline 1 & Warm-up, taxi and take-off & $m_{1} / m_{0}$ \\
2 & Climb and accelerate & $m_{2} / m_{1}$ \\
3 & Cruise & $m_{3} / m_{2}$ \\
4 & Descent for landing & $m_{4} / m_{3}$ \\
5 & Landing and taxi & $m_{5} / m_{4}$ \\
\hline
\end{tabular}

Table 1 Flight mission segments and mass fractions.

For the cruise flight segment a constant flight speed $V$ and a given constant lift coefficient $C_{L}$ have been assumed. The flight speed $V$ is determined by the selected design cruise Mach number $M a$ and the flight altitude $H$ at the beginning of cruise flight. In combination with the assumption of constant thrust specific fuel consumption $T S F C$ this leads to the well known Breguet range equation:

$$
R=\frac{1}{g} \frac{V}{T S F C} \frac{L}{D} \ln \frac{m_{2}}{m_{3}}
$$

The lift-to-drag ratio $L / D$ of the aircraft for the given lift coefficient $C_{L}$ and the wing mass $m_{W}$ are results of the parallel static aeroelastic analysis. Furthermore, the selected flight mission corresponds to the design mission. The outcome of this is that the aircraft mass $m_{0}$ at the start of the mission is equivalent to the maximum take-off mass $m_{M T O}$. For an aircraft the maximum take-off mass $m_{M T O}$ is the sum of the residual mass $m_{\text {Res }}$ (structural mass without the wing), the wing mass $m_{W}$, the payload $m_{P}$, the fuel mass $m_{F}$ and the reserve fuel mass $m_{F, r e s}$ :

$$
m_{M T O}=m_{R e s}+m_{W}+m_{P}+m_{F}+m_{F, r e s}
$$

In the presented applications the maximum take-off mass $m_{M T O}$ is held constant. Furthermore, the residual mass ratio $m_{\text {Res }} / m_{M T O}$ is also assumed to be constant, because the optimization is limited to the wing. In accordance with the simple model of the flight mission, the reserve fuel mass fraction $m_{F, r e s} / m_{F}$ is assumed to be constant as well. The fuel mass $m_{F}$ corresponds to the fuel mass which is required for the design mission and has been calculated with the following equation:

$$
m_{F}=m_{0}-m_{5}=m_{M T O}-m_{5}
$$


The objective function has to be selected based on the lift-to-drag ratio and the wing mass. Options for this selection are the minimization of fuel burn for a given range or the maximization of range for a given payload. Thereby, the objective function has to be derived for fixed maximum take-off mass.

For the transfer of the simulation results to the aircraft level the three following assumptions have been made.

Firstly, it has been assumed that the tailplane lift coefficient $C_{L, T}$ is constant. This means that the adaptation of tailplane lift for aircraft trimming has been neglected. The sum of wing and fuselage lift coefficients $C_{L, W}+C_{L, F}$ results from the flow simulation and matches the prescribed target lift coefficient for the cruise flight.

Secondly, a constant sum of tailplane and engine cowling drag coefficients (here denoted by $C_{D, r e s}$ ) has been assumed. The sum of wing and fuselage drag coefficients $C_{D, W}+C_{D, F}$ is a result of the flow simulation and includes pressure and viscous parts. With these assumptions the aerodynamic performance in terms of lift-to-drag $L / D$ ratio is calculated with the following equation:

$$
\frac{L}{D}=\frac{C_{L}}{C_{D}}=\underbrace{\frac{\overbrace{C_{L, W}+C_{L, F}}^{\text {flow simulation }}+\overbrace{C_{L, T}}^{=\text {const. }}}{\underbrace{}_{C_{D, \text { res }}=\text { const. }}+C_{D, F}}+\underbrace{C_{D,}}_{C_{D, T}+C_{D, E}}}_{\text {flow simulation }}
$$

Thirdly, the wing mass $m_{W}$ is the sum of the wing box mass $m_{W, b o x}$ and the secondary wing masses $m_{W, s e c}$. The secondary wing mass consists of the wing leading and trailing edge masses, which have been prescribed in terms of mass per projected area. Additionally, the wing box mass is computed based on the sized finite element (FE) model and is multiplied by a correction factor of 1.25 to get a more realistic wing mass. This correction factor accounts for additional structural mass, which is not modeled in the idealized wing box model.

\subsection{Parametric Model}

For the parameterization of the aircraft the Common Parametric Aircraft Configuration Schema (CPACS) [31] has been selected. This aircraft parameterization scheme uses the widely spread Extensible Markup Language (XML). Hence, the CPACS dataset represents a hierarchical organized and human readable file format.

The usage of CPACS offers a generic and fully parametric description of the aircraft. The geometrical description in CPACS is section based and developed for lowfidelity tools in conceptual design. For the usage in the context of high-fidelity simulation methods this geometrical description is not accurate enough. Therefore, some extensions have been introduced to the geometry description in CPACS through the definition of guide curves. These guide curves describe the surface geometry between the fuselage and wing sections respectively and will be used for the surface 
lofting. The resulting quality of the outer surface geometry is therefore appropriate for aerodynamic simulations with CFD methods.

In CPACS the inner geometry is defined based on the outer geometry description. This includes for example the parametric arrangement of spars and ribs. Also the used materials with their properties have to be defined in the CPACS dataset. The structural model generation process is linked to the CPACS dataset and is introduced in Sect. 2.5.

For the aerodynamic simulations a CAD model has been built automatically within the commercial software system CATIA ${ }^{\circledR}$ V5 based on the geometry description in CPACS. This parametric CAD model represents an equivalent representation of the geometrical description in CPACS with the same parametric description. The main task of the CAD model is the computation of the resulting surfaces and intersections for a given set of geometrical parameters in CPACS. In addition the CAD model includes the auxiliary geometry for the aerodynamic grid generation process.

This approach allows the fast and automated construction of a parametric CAD model, which provides the necessary interfaces to the CPACS dataset and the aerodynamic grid generation. Furthermore, the parametric CAD model allows fast and robust geometrical changes based on the CPACS parameters for a fixed aircraft topology.

\subsection{Aerodynamic Grid Generation Process}

The automated CAD model generation in CATIA $^{\circledR}$ includes the construction of the auxiliary geometry for the structured grid generation as mentioned before. Additionally, this CAD model generation program writes the control script for the structured aerodynamic grid generation using the commercial program Pointwise ${ }^{\circledR}$.

In combination with the generated control script the extended CAD model forms the input for the automatic aerodynamic grid generation with Pointwise ${ }^{\circledR}$. The control script includes all commands for the automatic generation of the structured aerodynamic grid.

In Fig. 3 the surface grid of the reference aircraft configuration is shown as an example. It also includes some details of the leading and trailing edge.

To minimize the number of grid points an O-O-topology is used. Each airfoil section is discretized with 170 points. The resulting aerodynamic grid consists of $2.5 \cdot 10^{6}$ points. This grid resolution represents an appropriate trade-off between accuracy and computing effort for wing optimizations.

The introduced approach allows the fast and automatic grid generation for geometrical changes controlled by design parameters within the optimization loop. Furthermore, the number of grid points is kept constant and the optimization process can be accelerated by using a fully converged flow solution as the starting point for solving the flow field around the modified aircraft geometry. With the usage of structured aerodynamic grids the grid dependent numerical noise is very low for geometrical changes, which is essential for accurate optimization results. 


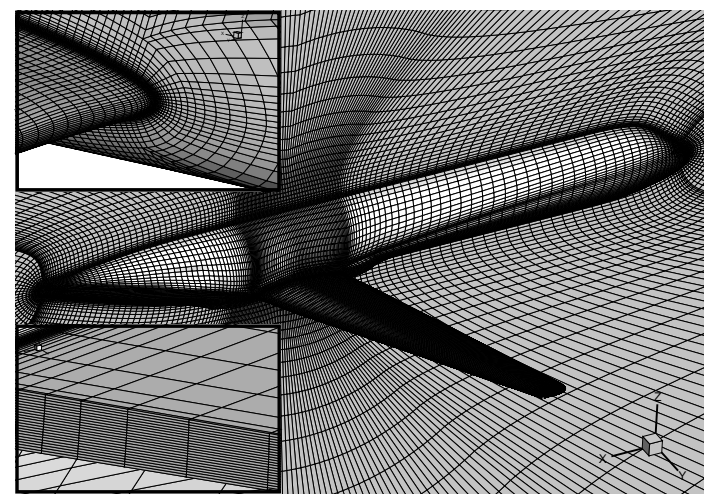

Fig. 3 Aerodynamic surface grid of the reference aircraft configuration with some details of the leading and trailing edge.

The actual implementation of the automated structured grid generation process is limited to the wing-fuselage configuration. However, the introduced procedure is of general applicability to aerodynamic grid generation in the context of MDO.

\subsection{Flow Solver}

The transonic flow around the wing-fuselage configuration is simulated with the DLR TAU-code [32], [33], [34], which has been developed at the DLR Institute of Aerodynamics and Flow Technology. The TAU-code solves the compressible, three-dimensional Reynolds-averaged Navier-Stokes equations. It is a well established tool for aerodynamic applications at DLR, universities and aerospace industry [35], [36], [4]. The TAU-code uses a vertex centered dual mesh formulation. For spatial approximation, a finite volume method with second order upwind or central discretization is used.

For the flow simulation within the aerostructural process chain the central discretization schema and the negative Spalart-Allmaras turbulence model [37] is currently being used.

\subsection{Structural Model Generation Process}

For the generation of structure models, the software DELiS (Design Environment for thin-walled Lightweight Structures) has been selected. The core of DELiS is a parametric model generator that supports various levels of detail. Based on a CPACS dataset, DELiS creates an abstract and object oriented model of the aircraft. This 
model contains all the structurally relevant CPACS information and enriches it with required data for finite elements. Due to the abstract and FE-centric definition of the lightweight structure, models for various FE solvers can be created, such as MSC Nastran ${ }^{\mathrm{TM}}$ and ANSYS ${ }^{\circledR}[38]$.

In Sect. ?? the structural model generation process is described in more detail.

\subsection{Structural Analysis and Sizing}

The aim of the structural sizing and optimization process is the minimization of the wing box mass $m_{W, b o x}$ with respect to a set of failure criteria. Based on the CPACS file an FE model of the wing is automatically generated as described in Sect. ??. With the external loads, which are calculated within the flow simulation and afterwards mapped onto the FE model, the internal loads are calculated with linear-static FE calculations. Subsequently the FE model with its geometry, material properties and loads is passed to the sizing and optimization module.

The sizing and optimization module is described in Sect. ??. Structure mechanical criteria for global buckling, local buckling and maximum strain for skin and stiffener are used for the sizing of the structural components. All criteria are evaluated at ultimate load. Damage tolerance constraints are covered by adapted strain allowables. For the strain allowable at ultimate load a conservative value of $3500 \mu \mathrm{m} / \mathrm{m}$ has been chosen as proposed in Military Handbook [39]. Furthermore criteria from manufacturing and operations like minimum and maximum ply share in $0^{\circ} / 90^{\circ} /+45^{\circ} /-45^{\circ}$ direction, minimum and maximum height for stringer webs and a minimum skin thickness for repair are considered.

The component sizing itself is performed within the commercial computer-aided engineering (CAE) software HyperSizer ${ }^{\circledR}$ [40]. The structural analysis and sizing process is iterated until all failure criteria are fulfilled and the mass change is lower than the convergence threshold.

\subsection{Fluid-Structure Coupling}

The fluid-structure interaction loop to be carried out in each of the parallel static aeroelastic analyses of Fig. 1 involves the following operations:

1. Compute the aerodynamic loads on the given CFD grid for every load case,

2. Interpolate the loads from the CFD surface grid to the structural model,

3. Perform the structural sizing (once the loads of all load cases are available),

4. Compute the structural deformations for the newly sized structure for every load case and

5. Adjust the CFD volume grid according to the resulting structural deformations. 
Then the loop starts over again. In step 2, an efficient classical nearest-neighbor interpolation is applied. It ensures equilibrium of forces on fluid and structural side. The existing defect in the equilibrium of moments is negligible. In step 5, a fast and robust grid deformation method is used which is based on the scattered data interpolation technology using radial basis functions. Based on the occurring structural deformations, a volume spline is determined which is then evaluated in parallel at all CFD volume grid points. Consult the publication by Barnewitz [41] for more detailed information on the grid deformation method.

The outlined fluid-structure interaction procedure is scripted in the FlowSimulator environment. The FlowSimulator has been designed particularly for massivelyparallel multidisciplinary simulations with high-fidelity tools [42]. It is being jointly developed by Airbus, ONERA, DLR and universities. Its core, a C++ layer, provides parallel data containers and associated methods that support an efficient in-memory data exchange between involved process components. A Python scripting layer representing the users' level of access facilitates a fast creation of complex multidisciplinary process chains [43].

For the convergence of the fluid-structure coupling loop several convergence criteria have been used in parallel. A list of all considered physical quantities and their corresponding convergence criteria is shown in Table 2. If all these convergence criteria are fulfilled simultaneously, the aeroelastic equilibrium will be considered as having been achieved and the fluid-structure coupling loop will be terminated.

\begin{tabular}{|c|c|c|}
\hline Physical quantity & & Convergence criterion $^{a}$ \\
\hline Lift-to-drag ratio & $L / D$ & $\frac{\Delta(L / D)}{L / D} \leq 0.001$ \\
\hline Wing mass & $m_{W}$ & $\frac{\Delta m_{W}}{m_{W}} \leq 0.005$ \\
\hline Fuel consumption & $F C=m_{F} /\left(R \cdot m_{P}\right)$ & $\frac{\Delta F C}{F C} \leq 0.002$ \\
\hline
\end{tabular}

Table 2 Convergence criteria of the fluid-structure coupling.

The selected values represent an appropriate trade-off between accuracy and computing time for the wing optimizations. The application of the process chain shows 4-8 fluid-structure coupling iterations $n_{c p l}$ in practice to reach convergence. Fig. 4 gives an example for the fluid-structure coupling convergence. Thereby, the used convergence criteria are shown as error bars.

The increase of wing mass at the beginning of the fluid structure coupling can be explained with the aeroelastic bending-torsion coupling of the forward swept wing. With increasing bending deformation the center of lift moves outboard and the resulting structural load increases. Additionally, Fig. 4 shows a decreasing lift-to-drag ratio under cruise flight conditions. This is a consequence of the elastic wing deformations. The convergence of the fuel consumption is reached after 4 fluid-structure coupling iterations. With the usage of several convergence criteria for the fluid- 


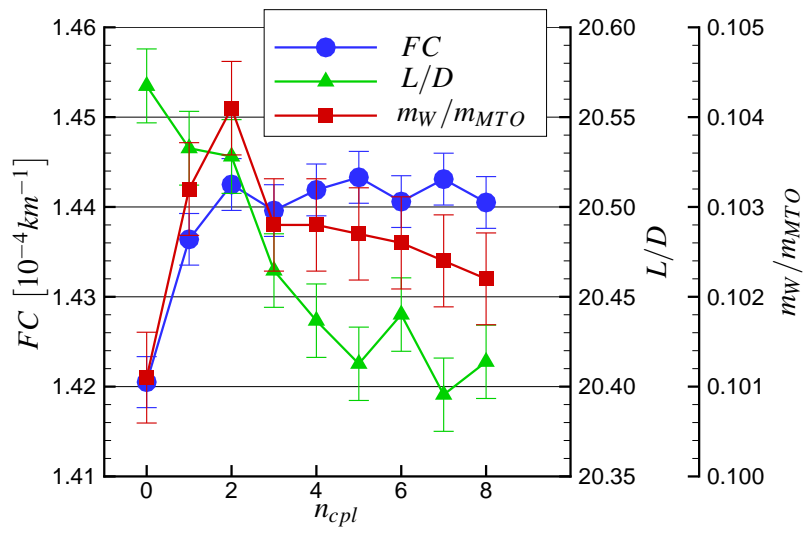

Fig. 4 Fluid-structure coupling convergence with used convergence criteria as error bars.

structure coupling up to the aeroelastic equilibrium the comparability of results for different geometries can be guaranteed within the aerostructural wing optimization.

\subsection{Optimization Method}

To control the process chain the program POT (Powerful Optimization Toolkit) [44] has been integrated. This program has been developed by the DLR Institute of Aerodynamics and Flow Technology and provides several optimization methods.

A surrogate based optimization (SBO) method has been selected for the aerostructural wing optimizations. This optimization method searches the global optimum and offers a high level of robustness. A similar optimization method named EGO (Efficient Global Optimizer) has been introduced by Jones et al. [45] and is discussed in Forrester et al. [46].

The optimization method starts with a design of experiments (DoE) for a selected number of samples. For the calculated objective function values, a surrogate model based on kriging [47] is built. This surrogate model is able to model nonlinear function behavior and includes a statistical error estimation.

The resulting surrogate model is then used for the optimization with a hybrid optimization strategy. Thereby, the expected improvement (EI) is used as the objective function. The optimization starts with a global optimization method and the localization of the optimum is improved by the application of a local optimization method. For the resulting global optimum of the surrogate model a recalculation is performed. The result of this recalculation is then used to improve the surrogate model. The described procedure is iterated until convergence is reached. 


\section{Reference Aircraft Configuration}

Within the scope of the DLR project LamAiR [20] an aerostructural wing design of an NLF forward swept wing for short and medium range transport aircraft has been performed [22]. It has been shown, that the forward swept wing design enables for wide extend of laminar flow at transonic flight conditions. By aeroelastic tailoring of the composite wing structure, a divergence free design has been achieved.

For the present study of aerostructural wing design and optimization, the LamAiR aircraft configuration has been selected as the reference. Furthermore, the top level aircraft requirements and the design mission are identical to this aircraft configuration. Table 3 gives an overview on the top level aircraft requirements.

\begin{tabular}{lll}
\hline Design cruise Mach number & $M a$ & 0.78 \\
Design mission payload & $m_{P}$ & 150 passengers \\
Design range & $R$ & $4815 \mathrm{~km}$ \\
\hline Maximum payload & $m_{P, \max }$ & 150 passengers and 5 t cargo \\
Range with maximum payload & $R_{m P}$ & $3056 \mathrm{~km}$ \\
\hline Take-off field length & $s_{T O F L}$ & $\approx 1900 \mathrm{~m}$ \\
Landing field length & $s_{L F L}$ & $\approx 1600 \mathrm{~m}$ \\
\hline Propulsion & - & CFM56 class turbofan \\
Airport conformity & - & FAA Group III and ICAO Code C \\
\hline
\end{tabular}

Table 3 Top level aircraft requirements of the reference aircraft configuration.

The reference aircraft configuration has a low wing, rear mounted engines and a T-tail as shown in Fig. 5. To fulfill the surface requirements for laminar flow and the requirements for take-off and landing performance, the reference aircraft features a smart leading edge high-lift system as proposed by the DLR Institute of Composite Structures and Adaptive Systems [48].

The selected reference aircraft configuration represents a short and medium range commercial aircraft in the Airbus A320 and Boeing 737 class.

Key figures of the aircraft's flight envelope are summarized in Table 4. Flight envelope data give the basis for the selection of critical load cases for the structural sizing of the wing box.

The aerodynamic wing design of the reference aircraft configuration has been published by Kruse et al. [22]. With the objective of drag reduction by maximizing the extension of laminar flow for a design cruise Mach number of $M a=0.78$, the choice for a forward swept wing configuration is well-founded. For tapered wings, the forward swept wing design allows the favorably low leading edge sweep angle of $\varphi_{L E}=-17^{\circ}$ for a passive control of cross flow instabilities in the leading edge region. Simultaniously, a sufficiently high sweep angle near the midchord shock position in the order of $\varphi=-25^{\circ}$ is maintained, to meet the requirement of low wave drag in cruise flight for realistic wing thickness distributions and lift coefficients. Regarding these aspects, the forward swept wing design offers a clear ad- 

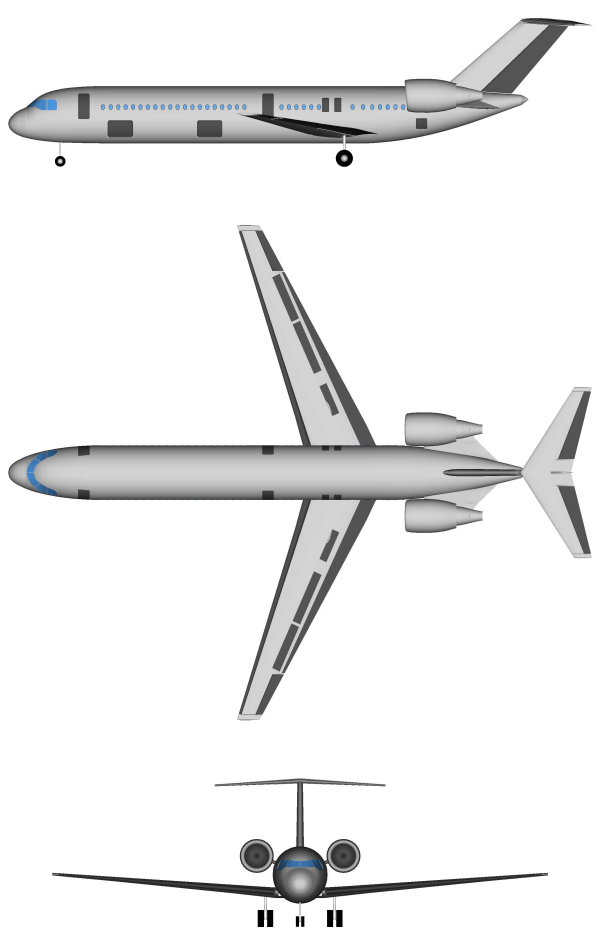

Fig. 5 Reference aircraft configuration.

\begin{tabular}{llc}
\hline Altitude & & \\
\hline Maximum flight altitude & $H_{\max }$ & $41000 \mathrm{ft}=12500 \mathrm{~m}$ \\
\hline Design speeds & & \\
\hline Maximum operating Mach number & $M a_{M O}$ & 0.8 \\
Maximum operating limit speed & $V_{M O, C A S}$ & $350 \mathrm{kn}$ \\
Design diving Mach number & $M a_{D}$ & 0.87 \\
Design diving speed & $V_{D, C A S}$ & $395 \mathrm{kn}$ \\
\hline
\end{tabular}

Table 4 Key figures of the flight envelope.

vantage for NLF design under transonic cruise flight conditions in comparison to backward swept configurations. Some penalty in high-lift efficency is expected due to the pronounced sweep of the trailing edge. However, the straigt trailing edge of the mono-trapezoid wing planform and the rear mounted engine layout allow an efficient continuous trailing edge flap design. Aerodynamic cruise performance is shown to benefit from up to $19 \%$ drag reduction in comparison to a conventional backward swept aircraft design. The predicted laminar-turbulent transition 
locations at the design point $\left(M a=0.78\right.$ and $C_{L}=0.5$ at $\left.F L=350\right)$ reach values between $x_{T} / c=45 \%$ and $x_{T} / c=60 \%$ on the wing's upper surface and values of $x_{T} / c=50 \%$ on the lower surface.

The wing box structure of the reference aircraft configuration has been derived from the structural design and sizing of the LamAiR configuration [22]. For the composite wing box the material properties of the CYCOM $^{\circledR}$ 977-2 Epoxy Resin System from Cytec Industries Inc. have been used. The percentage ply share of the composite material is shown in Table 5 for the wing box of the reference aircraft configuration.

\begin{tabular}{lcc}
\hline & $\begin{array}{c}\text { Dimensionless span coordinate } \\
\eta=2 y / b\end{array}$ & $\begin{array}{c}\text { Percentage ply share } \\
0^{\circ} / \pm 45^{\circ} / 90^{\circ}\end{array}$ \\
\hline \multirow{3}{*}{ Upper skin } & $0.0000-0.3876$ & $70 / 20 / 10$ \\
& $0.3876-0.8157$ & $60 / 20 / 20$ \\
& $0.8157-0.8871$ & $50 / 30 / 20$ \\
& $0.8871-0.9584$ & $40 / 40 / 20$ \\
\hline \multirow{2}{*}{ Lower skin } & $0.0000-0.3520$ & $70 / 20 / 10$ \\
& $0.3520-0.7444$ & $60 / 20 / 20$ \\
Front spar & $0.7444-0.7801$ & $50 / 30 / 20$ \\
& $0.7801-0.9584$ & $40 / 40 / 20$ \\
\hline Rear spar & $0.0000-0.6730$ & $50 / 30 / 20$ \\
& $0.6730-0.9584$ & $40 / 30 / 30$ \\
\hline \multirow{2}{*}{ Ribs } & $0.0000-0.9584$ & $70 / 20 / 10$ \\
& $0.0000-0.2101$ & $10 / 80 / 10$ \\
& $0.2101-0.3163$ & $20 / 60 / 20$ \\
& $0.3163-0.3876$ & $30 / 50 / 20$ \\
& $0.3876-0.4947$ & $40 / 40 / 20$ \\
& $0.4947-0.9584$ & $60 / 20 / 20$ \\
\hline
\end{tabular}

Table 5 Percentage ply share of the wing box composite material.

\section{Design Task}

\subsection{Design Parameters and Constraints}

The parametric model of the reference aircraft configuration is generated based on the selection of 12 fuselage sections and 9 wing sections. Additionally, 5 guide curves have been used for the geometry description between the fuselage sections and 3 guide curves for the geometry description between the wing sections. Thereby, the guide curves of the wing form the wing leading edge and the upper and lower line of the blunt trailing edge. In Fig. 6 the positions of the selected wing sections are shown for the reference aircraft configuration. 
The selected design parameters for the wing design studies and the wing optimization are:

- Aspect ratio $A$,

- Taper ratio $\lambda$,

- Twist and thickness distribution $\varepsilon_{i},(t / c)_{i}$,

- Orthotropy angles of the composite material $\varphi_{O D, \text { middle }}$ and $\varphi_{O D, \text { outboard }}$.

For the variation of the twist and thickness distribution the values in 4 wing sections have been used respectively. This leads to a total number of 12 design parameters.

The optimizer does not directly control the design parameters. Scaling factors are used for the control of the aspect ratio, taper ratio and thickness distribution, and differences are used for the control of the twist distribution and the orthotropy angles. Thereby, the scaling factors and the differences are based on the corresponding values of the reference aircraft configuration.

In Fig. 6 the selected definition of design parameters is shown. The twist distribution parameters control the twist angles $\varepsilon_{i}$ in the wing sections 3,4,6 and 9. For the control of the thickness distribution the thickness parameters $(t / c)_{i}$ of the wing sections 1,4,6 and 8 have been used. In the wing sections between the values for the twist angle and relative thickness are calculated by linear interpolation of the corresponding scaling factors and differences.

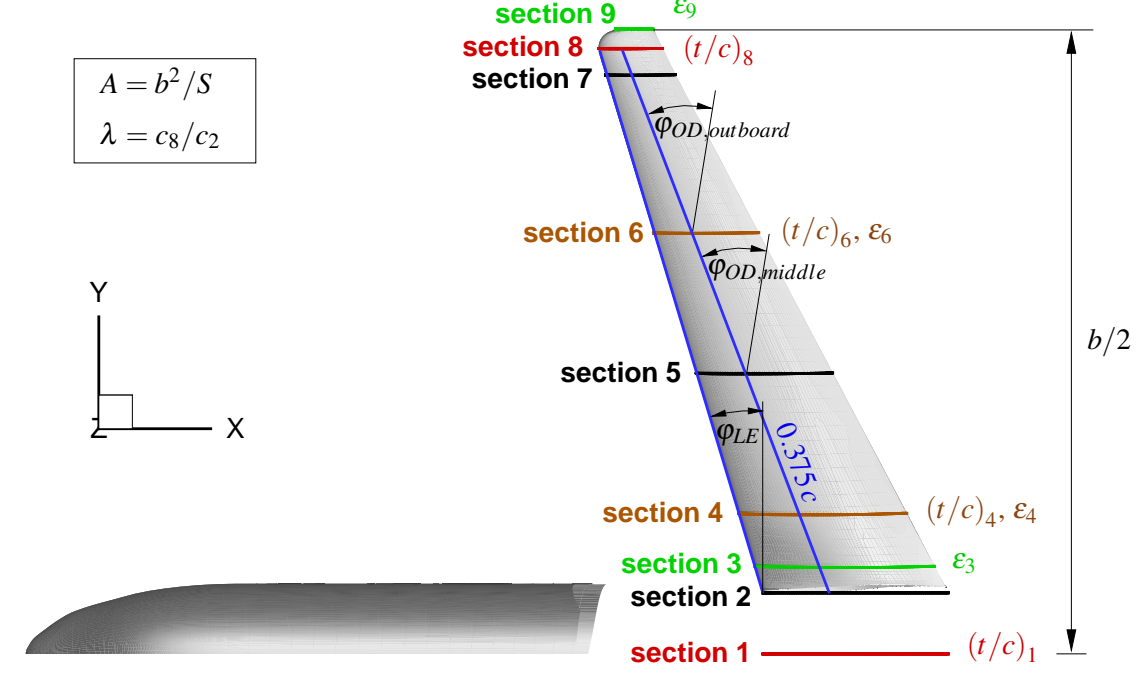

Fig. 6 Definition of design parameters.

For the aeroelastic tailoring of the wing the complete orthotropic material including the stringers of the upper and lower wing box skin is rotated. The orthotropy an- 
gle of the composite material $\varphi_{O D}$ is defined relative to the mean line of the wing box as shown in Fig. 6. In the unswept center wing and the inboard wing the orthotropy angle of the composite material has been held constant. The aeroelastic tailoring has been applied to the middle and outboard wing regions. This is achieved by using the orthotropy angles of the composite material $\varphi_{O D \text {,middle }}$ and $\varphi_{O D \text {,outboard }}$ to control the bend-twist-coupling of the wing. Thereby, the middle wing starts at approximately $40 \%$ wing span and ends at approximately $70 \%$ wing span. Consequently the outboard wing starts at approximately $70 \%$ wing span.

The optimization constraints are listed in Table 6 and are based on the top level aircraft requirements of Table 3 and the results of the conceptual aircraft design published in [22]. This includes the specifications of the maximum take-off mass $m_{M T O}$, wing loading $m_{M T O} / S$ and the cruise Mach number $M a$.

\begin{tabular}{lll}
\hline Aircraft & & \\
\hline Maximum take-off mass & $m_{M T O}$ & $73365 \mathrm{~kg}$ \\
Maximum payload & $m_{P, \text { max }}$ & $19250 \mathrm{~kg}$ \\
Wing loading & $m_{M T O} / S$ & $556 \mathrm{~kg} / \mathrm{m}^{2}$ \\
Residual mass ratio & $m_{R e s} / m_{M T O}$ & 0.4604 \\
Drag coefficient of tailplane and engine cowling & $C_{D, r e s}$ & 0.0025 \\
Specific mass of leading edge high lift device & $m_{l e} / S_{l e}$ & $30 \mathrm{~kg} / \mathrm{m}^{2}$ \\
Specific mass of trailing edge high lift device & $m_{t e} / S_{t e}$ & $50 \mathrm{~kg} / \mathrm{m}^{2}$ \\
Leading edge sweep angle & $\varphi_{L E}$ & $-16.8^{\circ}$ \\
Relative front spar position & $x_{F S} / c$ & 0.15 \\
Relative rear spar position & $x_{R S} / c$ & 0.60 \\
Number of ribs & $N_{R i b s}$ & $2 \cdot 27+1=57$ \\
\hline Design mission & & \\
\hline Mach number & $M a$ & 0.78 \\
Range & $R$ & $4815 \mathrm{~km}$ \\
Range cruise segment & $R_{23}$ & $3726 \mathrm{~km}$ \\
Lift coefficient aircraft & $C_{L}$ & 0.5 \\
Lift coefficient tailplane & $C_{L, T}$ & -0.0022 \\
Thrust specific fuel consumption & $T S F C$ & $0.0589 \mathrm{~kg} /(\mathrm{Nh})$ \\
Take-off and climb mass fraction & $m_{2} / m_{0}$ & 0.9589 \\
Descent and landing mass fraction & $m_{5} / m_{3}$ & 0.9906 \\
Reserve fuel mass fraction & $m_{F, r e s} / m_{F}$ & 0.4604 \\
\hline
\end{tabular}

Table 6 Constraints for the wing design studies and wing optimization.

For the structural sizing of the wing box three maneuver load cases with minimum and maximum load factors from the certification specifications CS-25/FAR 25 have been selected. The definitions of the cruise flight design point and the selected load cases are specified in Table 7 and are based on the flight envelope of the reference aircraft configuration.

The NLF wing sections have been adopted from the reference aircraft configuration. For the flow simulations, spanwise transition locations are prescibed at $x_{T} / c=0.3$ for the inboard wing and $x_{T} / c=0.4$ for the middle and outboard 


\begin{tabular}{lrcccc}
\hline Load case & $\begin{array}{c}\text { Altitude } \\
H\end{array}$ & $\begin{array}{c}\text { Mach number } \\
M a\end{array}$ & $\begin{array}{c}\text { Lift coefficient } \\
C_{L, W}+C_{L, F}\end{array}$ & $\begin{array}{c}\text { Aircraft mass } \\
m\end{array}$ & $\begin{array}{c}\text { Load factor } \\
n\end{array}$ \\
\hline Cruise $^{a}$ & $10668 \mathrm{~m}$ & 0.780 & 0.502 & $68640 \mathrm{~kg}$ & 1.0 \\
LC 2 & $0 \mathrm{~m}$ & $0.717^{b}$ & 0.374 & $73365 \mathrm{~kg}$ & 2.5 \\
LC 3 & $4725 \mathrm{~m}$ & 0.772 & 0.571 & $73365 \mathrm{~kg}$ & 2.5 \\
LC 4 & $0 \mathrm{~m}$ & $0.717^{b}$ & -0.149 & $73365 \mathrm{~kg}$ & -1.0 \\
\hline
\end{tabular}

${ }^{a}$ Design point with laminar-turbulent transition prescription

${ }^{b} V=1.2 \cdot V_{D}$ for divergence prevention from CS-25/FAR 25

Table 7 Cruise flight design point and load cases for the structural sizing of the wing.

wing. Furthermore, the leading edge sweep angle is limited to $\left|\varphi_{L E}\right| \leq 17^{\circ}$ to preclude excessive growth of crossflow instabilities and potential attachment line transition [17].

The topology of the wing box structure (relative spar positions and number of ribs) and the ply share of the composite material are transferred from the reference aircraft configuration. The values for this percentage ply share of the composite material are indicated in Table 5. Within the structural sizing process the wing box topology and the ply share of the composite material is held constant. The wing box mass $m_{W, b o x}$ resulting from the structural sizing process is multiplied by a factor of 1.25 to account for additional masses which are not modeled in the idealized finite element model [49]. This is required to obtain a realistic wing mass for the evaluation of the objective function.

\subsection{Objective Function}

Based on the simplified model for the flight mission as introduced in Sect. 2.1 the fuel consumption $F C$ has been selected as the figure of merit for the aerostructural wing optimization. The fuel consumption $F C$ is here defined in terms of fuel burn per range and payload $m_{F} /\left(R m_{P}\right)$ for a given range $R$.

The minimization of the fuel burn is an appropriate objective for the aerostructural wing optimization of future commercial aircraft as shown in [50].

For the calculation of the fuel consumption the required equations are listed in Table 8. Thereby, the fuel mass $m_{F}$ is computed from the given range $R$ and the lift-to-drag ratio $L / D$. The payload $m_{P}$ results from this fuel mass $m_{F}$ and the wing mass $m_{W}$. As mentioned before, the lift-to-drag ratio $L / D$ and the wing mass $m_{W}$ are outputs of the parallel static aeroelastic analysis. With all these calculated values the fuel consumption per range and payload $m_{F} /\left(R m_{P}\right)$ follows directly from the last equation shown in Table 8. 


\begin{tabular}{ll}
\hline Mass fraction cruise & $\frac{m_{3}}{m_{2}}=e^{-\frac{g T S F C R}{V(L / D)}}$ \\
Mass fraction fuel & $\frac{m_{F}}{m_{M T O}}=1-\frac{m_{3}}{m_{2}} \frac{m_{1}}{m_{M T O}} \frac{m_{2}}{m_{1}} \frac{m_{4}}{m_{3}} \frac{m_{5}}{m_{4}}$ \\
Mass fraction payload & $\frac{m_{P}}{m_{M T O}}=1-\frac{m_{\text {Res }}}{m_{M T O}}-\frac{m_{W}}{m_{M T O}}-\left(1+\frac{m_{F} \text { res }}{m_{F}}\right) \frac{m_{F}}{m_{M T O}}$ \\
Fuel consumption & $F C=\frac{1}{R} \frac{m_{F}}{m_{M T O}} \frac{m_{M T O}}{m_{P}}$ \\
\hline
\end{tabular}

Table 8 Equations for the calculation of fuel consumption.

\section{Wing Design Studies}

The wing design studies have been performed with the introduced process chain and the selected design parameters and constraints. Each study has been executed for a constant taper ratio and a constant orthotropy angle distribution of the composite material. In each design study wings with 2 to 3 aspect ratios, 2 to 3 thickness distributions and 2 twist distributions have been investigated.

The results for the orthotropy angle distribution of $\varphi_{O D}=\left(0^{\circ} ; 0^{\circ} ; 0^{\circ}\right)$ are summarized in Fig. 7 and Fig. 8 in terms of wing mass ratio $m_{W} / m_{M T O}$, lift-to-drag ratio $L / D$ and fuel consumption $F C$.

As expected, the increasing aspect ratio shows an increase of lift-to-drag ratio and wing mass ratio due to induced drag reduction and a higher level of structural loads. The results for different thickness distributions show the trend of increased lift-todrag ratios and wing mass ratios for reduced airfoil thicknesses. Furthermore, twist distributions with increased outboard loading lead to increased wing mass ratios.

The design mission fuel consumption depends on aerodynamic performance and structural wing mass ratio. Consequently, the minimization of design mission fuel consumption is equivalent to the search for the best trade-off between aerodynamic performance in terms of lift-to-drag ratio and structural wing mass ratio. It can be observed that different wing geometries with the same design mission fuel consumption exist. These solutions are equivalent with regard to the objective function. Additional criteria have to be considered for a further assessment.

In all figures the solutions for the baseline and the optimized wing geometries are included. The baseline wing geometry is transferred from the reference aircraft configuration, which is described in Sect. 3. Thereby, no aeroelastic tailoring has been considered. This means that the orthotropy angles of the composite material are set to $\varphi_{O D}=\left(0^{\circ} ; 0^{\circ} ; 0^{\circ}\right)$. The optimized wing geometry is the result of the wing optimization including aeroelastic tailoring, which is presented in Sect. 6 .

The influence of taper ratio variation can be observed by comparing the results of Fig. 7 and Fig. 8. This taper ratio reduction shows the trend to almost unchanged lift-to-drag ratios and decreased wing mass ratios. Only for the lower taper ratio of $\lambda=0.17$ the calculations with the high aspect ratio of $A=13.44$ have been performed. 


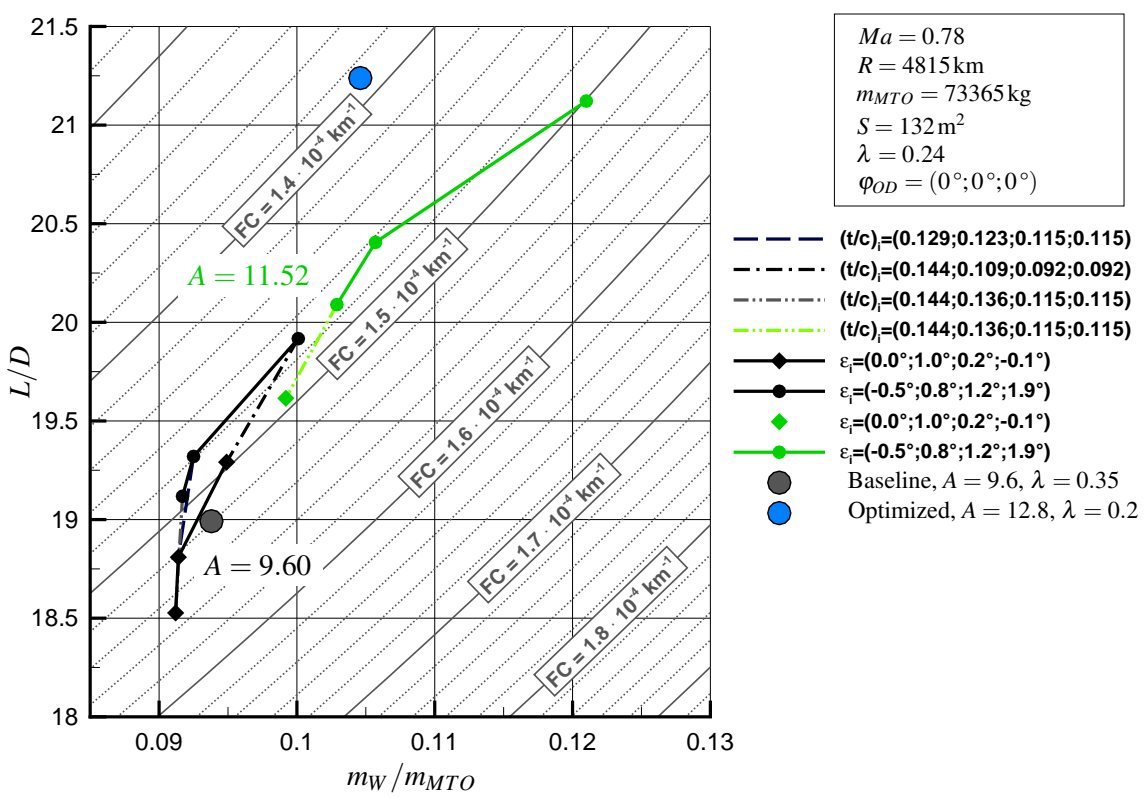

Fig. 7 Variation of aspect ratio, thickness and twist distribution for a taper ratio of $\lambda=0.24$ and an orthotropy angle distribution of $\varphi_{O D}=\left(0^{\circ} ; 0^{\circ} ; 0^{\circ}\right)$.

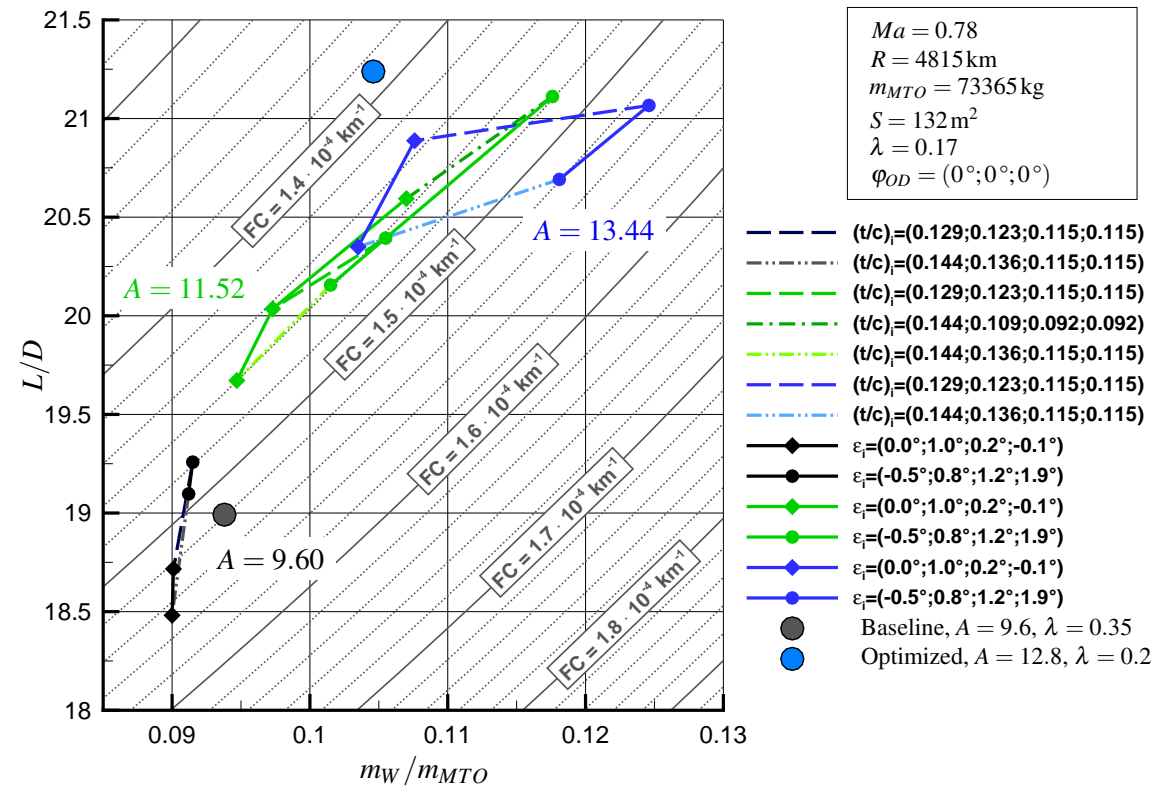

Fig. 8 Variation of aspect ratio, thickness and twist distribution for a taper ratio of $\lambda=0.17$ and an orthotropy angle distribution of $\varphi_{O D}=\left(0^{\circ} ; 0^{\circ} ; 0^{\circ}\right)$. 


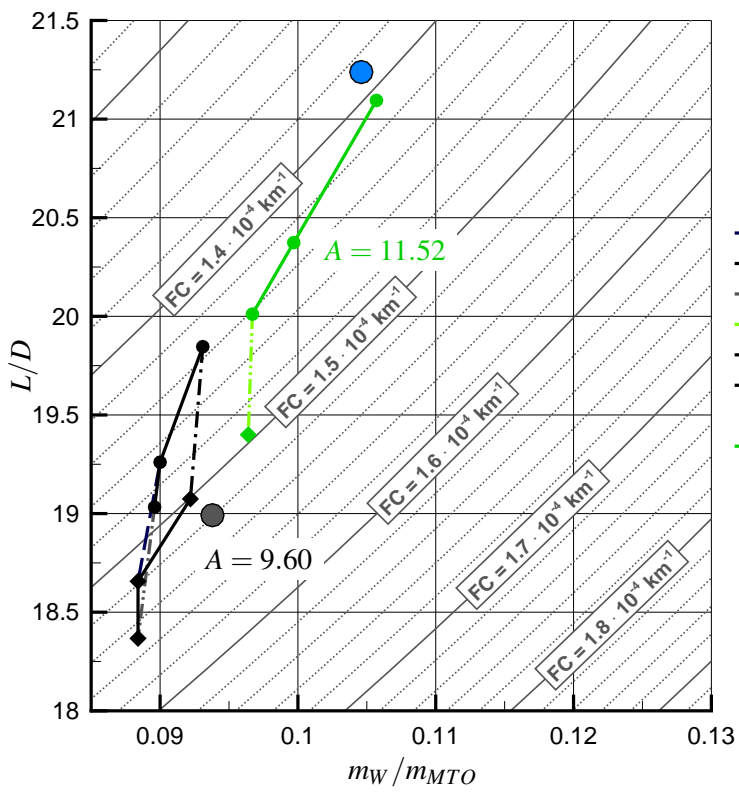

$M a=0.78$
$R=4815 \mathrm{~km}$
$m_{M T O}=73365 \mathrm{~kg}$
$S=132 \mathrm{~m}^{2}$
$\lambda=0.24$
$\varphi_{O D}=\left(0^{\circ} ;-5^{\circ} ;-5^{\circ}\right)$

- — $(\mathrm{t} / \mathrm{c})_{\mathrm{i}}=(0.129 ; 0.123 ; 0.115 ; 0.115)$

- . . . $(\mathrm{t} / \mathrm{c})_{\mathrm{s}}=(0.144 ; 0.109 ; 0.092 ; 0.092)$

...... $(\mathrm{t} / \mathrm{c})_{\mathrm{i}}=(0.144 ; 0.136 ; 0.115 ; 0.115)$

$(\mathrm{t} / \mathrm{c})_{\mathrm{i}}=(0.144 ; 0.136 ; 0.115 ; 0.115)$

$\longrightarrow \varepsilon_{\mathrm{i}}=\left(0.0^{\circ} ; 1.0^{\circ} ; 0.2^{\circ} ;-0.1^{\circ}\right)$

$\longrightarrow \varepsilon_{1}=\left(-0.5^{\circ} ; 0.8^{\circ} ; 1.2^{\circ} ; 1.9^{\circ}\right)$

$\varepsilon_{1}=\left(0.0^{\circ} ; 1.0^{\circ} ; 0.2^{\circ} ;-0.1^{\circ}\right)$

$\varepsilon_{1}=\left(-0.5^{\circ} ; 0.8^{\circ} ; 1.2^{\circ} ; 1.9^{\circ}\right)$

Baseline, $A=9.6, \lambda=0.35$

Optimized, $A=12.8, \lambda=0.2$

Fig. 9 Variation of aspect ratio, thickness and twist distribution for a taper ratio of $\lambda=0.24$ and an orthotropy angle distribution of $\varphi_{O D}=\left(0^{\circ} ;-5^{\circ} ;-5^{\circ}\right)$.

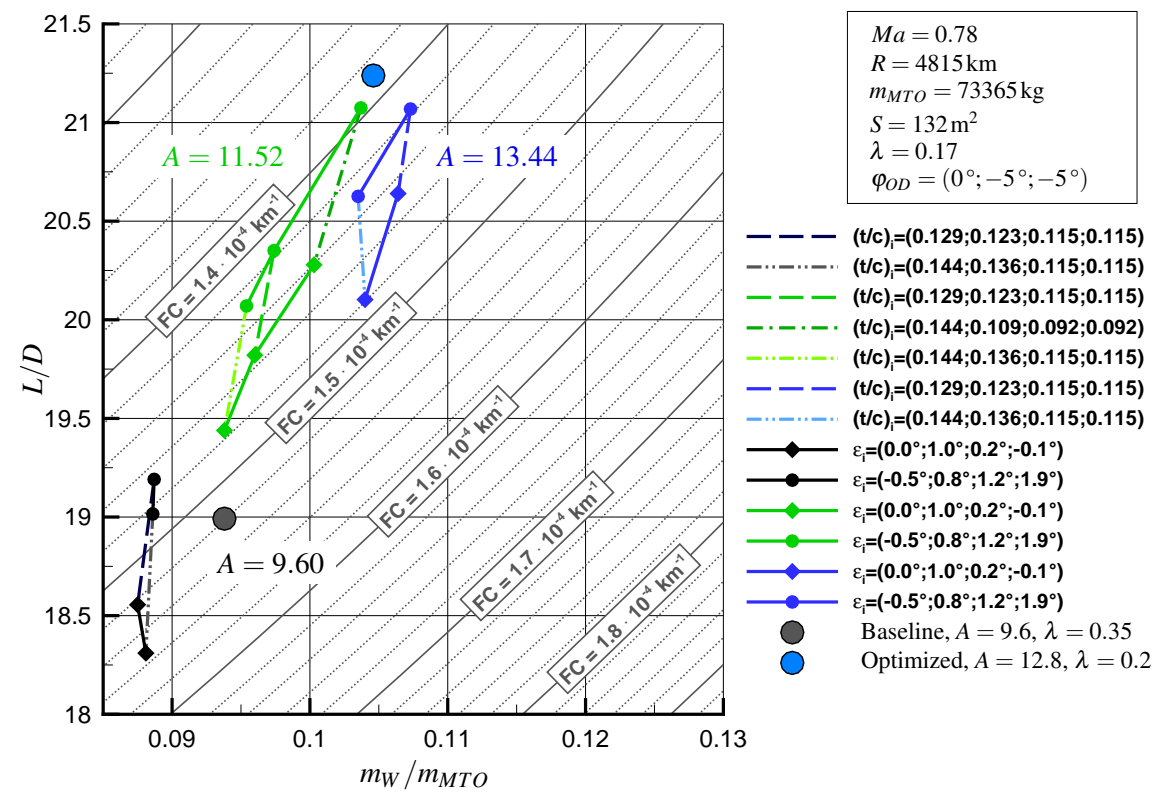

Fig. 10 Variation of aspect ratio, thickness and twist distribution for a taper ratio of $\lambda=0.17$ and an orthotropy angle distribution of $\varphi_{O D}=\left(0^{\circ} ;-5^{\circ} ;-5^{\circ}\right)$. 


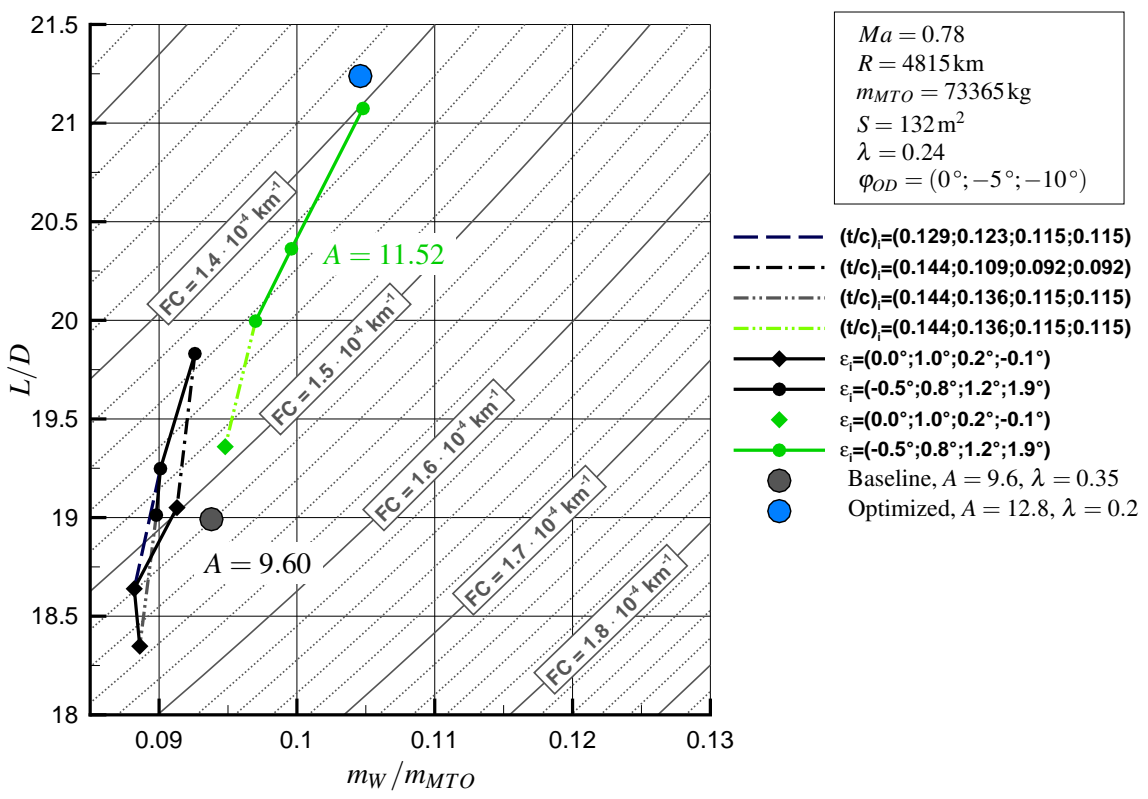

Fig. 11 Variation of aspect ratio, thickness and twist distribution for a taper ratio of $\lambda=0.24$ and an orthotropy angle distribution of $\varphi_{O D}=\left(0^{\circ} ;-5^{\circ} ;-10^{\circ}\right)$.

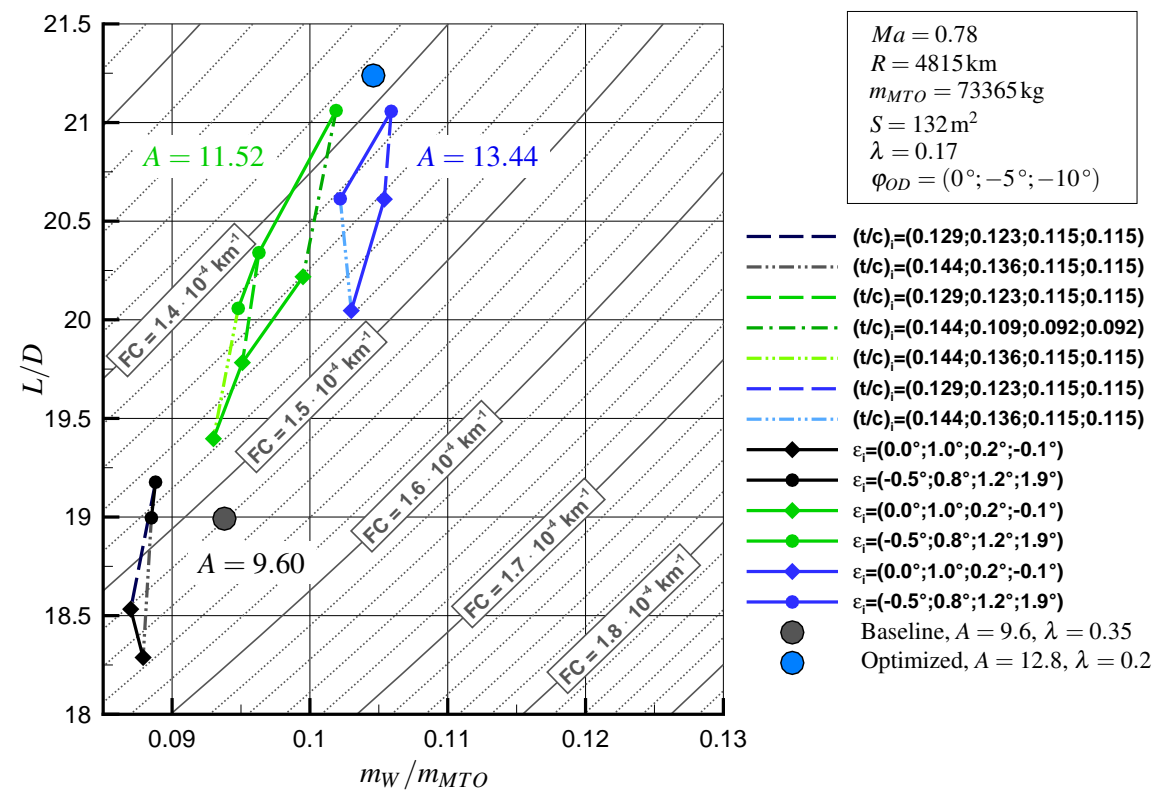

Fig. 12 Variation of aspect ratio, thickness and twist distribution for a taper ratio of $\lambda=0.17$ and an orthotropy angle distribution of $\varphi_{O D}=\left(0^{\circ} ;-5^{\circ} ;-10^{\circ}\right)$. 
To investigate the influence of aeroelastic tailoring the studies have been repeated for wings with different orthotropy angle distributions. The results for an orthotropy angle distribution of $\varphi_{O D}=\left(0^{\circ} ;-5^{\circ} ;-5^{\circ}\right)$ are shown in Fig. 9 and Fig. 10.

The aeroelastic tailoring leads to a significant wing mass reduction and similar aerodynamic performance. In comparison to the results with an orthotropy angle distribution of $\varphi_{O D}=\left(0^{\circ} ; 0^{\circ} ; 0^{\circ}\right)$ the results show the same trend of increased liftto-drag ratios and wing mass ratios for reduced airfoil thicknesses. The main difference can be observed for the twist distribution variations. In contrast to the results with an orthotropy angle distribution of $\varphi_{O D}=\left(0^{\circ} ; 0^{\circ} ; 0^{\circ}\right)$ the results for the aeroelastic tailored wings show that twist distributions with increased outboard loading lead to increased lift-to-drag ratios with minor effect to the wing mass ratios.

In Fig. 11 and Fig. 12 the results for the orthotropy angle distribution of $\varphi_{O D}=$ $\left(0^{\circ} ;-5^{\circ} ;-10^{\circ}\right)$ are presented. These results show further fuel consumption reductions in comparison to the results with an orthotropy angle distribution of $\varphi_{O D}=$ $\left(0^{\circ} ;-5^{\circ} ;-5^{\circ}\right)$. The reason for the fuel consumption reductions is the decrease of wing masses due to maneuver load reduction.

The best solutions of the wing design studies including aeroelastic tailoring achieve nearly the same fuel consumption as the optimized wing resulting from the wing optimization in Sect. 6.

\section{Wing Design Optimization}

The wing optimization has been performed successfully for the selected design parameters and constraints. Fig. 13 gives an overview of the wing optimization results in terms of fuel consumption $F C$, lift-to-drag ratio $L / D$, wing mass ratio $m_{W} / m_{M T O}$ and payload ratio $m_{P} / m_{M T O}$ depending on the aspect ratio $A$.

The increase of aspect ratio shows the trend of increasing lift-to-drag ratio and wing mass ratio. Minimum values for the fuel consumption can be observed for wings with an aspect ratio between 11 and 13. For the specified constraint of constant maximum take-off mass the payload ratio is an output of the process chain and reaches maximum values for aspect ratios between 10 and 12 .

The wing optimization has been performed without a span limit. This leads to optimal wing geometries with wing spans greater than the span limit of $b \leq 36 \mathrm{~m}$ for FAA Group III and ICAO Code C aircraft. Technical solutions for folded wingtips exist and have to be considered for wings with the highest level of fuel efficiency. The span limit of FAA Group III and ICAO Code C aircraft is additionally drawn in Fig. 13. Furthermore, the wing with minimum fuel consumption is marked in Fig. 13 and further referred to as "optimized".

In Table 9 the wing planform parameters resulting from the optimization are shown for the baseline and the optimized wing. The aspect ratio $A$ of the optimized wing has been increased in comparison to the baseline wing. Furthermore, the taper ratio $\lambda$ of the optimized wing is lower than the value of the baseline wing. 


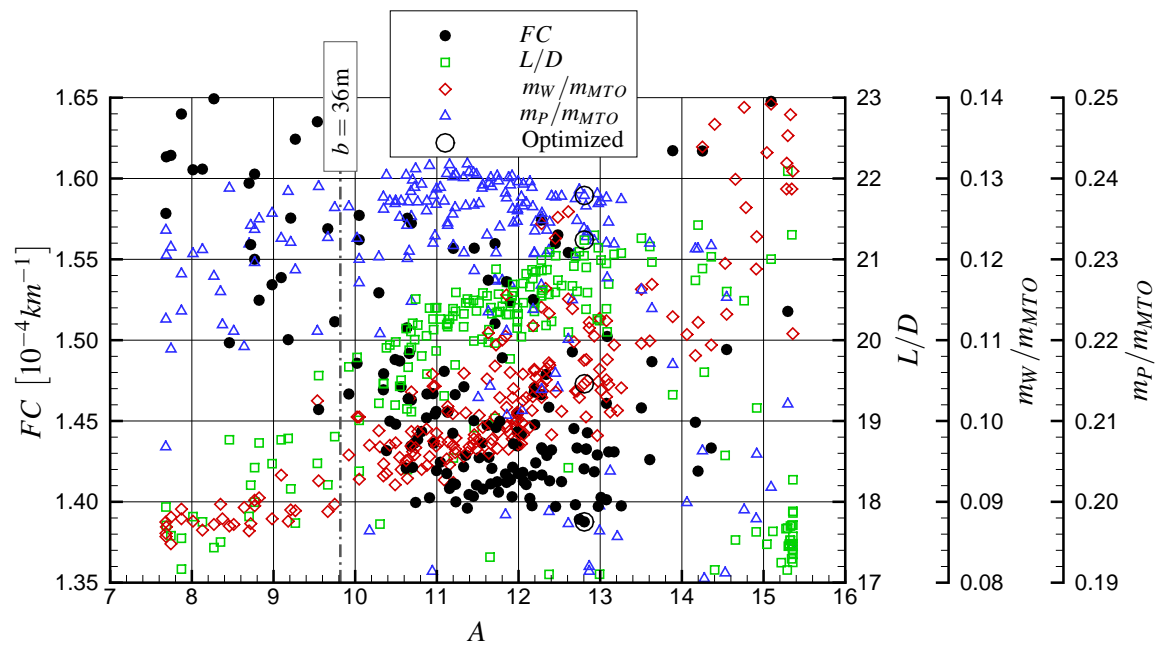

Fig. 13 Overview of wing optimization results.

\begin{tabular}{lllll}
\hline & & Baseline & Optimized & Difference \\
\hline Aspect ratio & $A$ & 9.601 & 12.806 & $+33.4 \%$ \\
Taper ratio & $\lambda$ & 0.345 & 0.196 & $-43.1 \%$ \\
Orthotropy angle middle wing & $\varphi_{O D, \text { middle }}$ & $0.0^{\circ}$ & $-4.7^{\circ}$ & $-4.7^{\circ}$ \\
Orthotropy angle outboard wing & $\varphi_{O D, \text { outboard }}$ & $0.0^{\circ}$ & $-5.8^{\circ}$ & $-5.8^{\circ}$ \\
\hline Lift-to-drag ratio & $L / D$ & 18.992 & 21.239 & $+11.8 \%$ \\
Wing mass ratio & $m_{W} / m_{M T O}$ & 0.0938 & 0.1046 & $+11.5 \%$ \\
Fuel mass ratio & $m_{F} / m_{M T O}$ & 0.2121 & 0.1972 & $-7.0 \%$ \\
Payload ratio & $m_{P} / m_{M T O}$ & 0.2338 & 0.2379 & $+1.8 \%$ \\
\hline Fuel consumption & $F C$ & $1.519 \cdot 10^{-4} \mathrm{~km}^{-1} 1.388 \cdot 10^{-4} \mathrm{~km}^{-1}-8.6 \%$ \\
\hline
\end{tabular}

Table 9 Results of wing optimization for baseline and optimized wing.

In Fig. 14 the twist distributions of the baseline and optimized wing are shown for the undeformed jig-shape geometry. The twist angles of the optimized wing are nearly identical in the inboard and outboard regions in comparison to the baseline wing. In the middle wing region the twist angles of the optimized wing are slightly smaller than the twist angles of the baseline wing.

Fig. 15 shows the relative and absolute thickness distributions of the baseline and the optimized wing. The absolute thickness is nearly identical in the symmetry plane of both wings. With the exception of the symmetry plane and the wing tip the relative and absolute thickness of the optimized wing are decreased in comparison to the baseline wing. In principle the relative airfoil thickness reduction leads to aerodynamic performance improvement and the absolute airfoil thickness reduction 


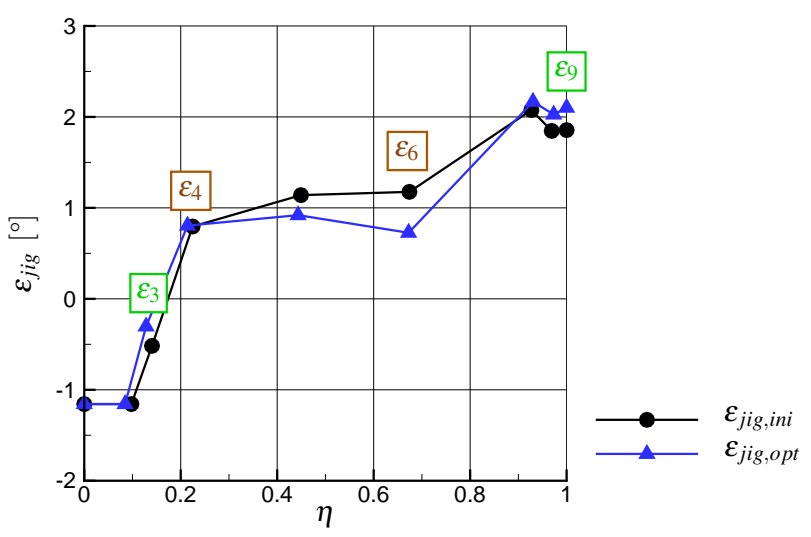

Fig. 14 Twist distributions for baseline and optimized wing.

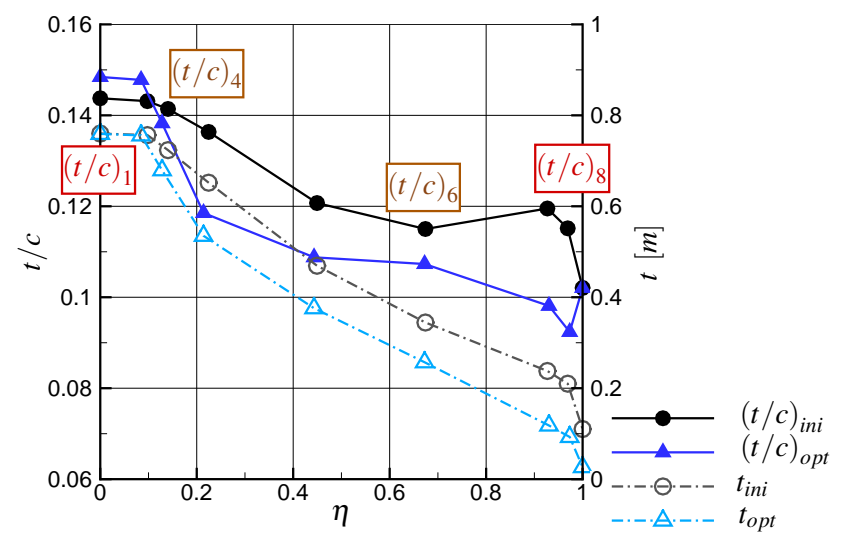

Fig. 15 Relative and absolute thickness distributions for baseline and optimized wing.

results in increased wing mass. Additionally, the thickness reduction of the wing leads to a smaller fuel tank volume.

The optimization results for the lift-to-drag ratio, the wing mass ratio, the fuel mass ratio, the payload ratio and the fuel consumption are also given in Table 9. These results show an increased aerodynamic performance in terms of lift-to-drag ratio $L / D$ and simultaneously an increased wing mass ratio $m_{W} / m_{M T O}$ for the optimized wing in comparison to the baseline wing. The increased lift-to-drag-ratio can be explained with the induced drag reduction resulting from the increased span and leads to the reduced fuel mass ratio. It can be observed that the reduced fuel mass ratio $m_{F} / m_{M T O}$ overcompensates the increased wing mass ratio $m_{W} / m_{M T O}$. 

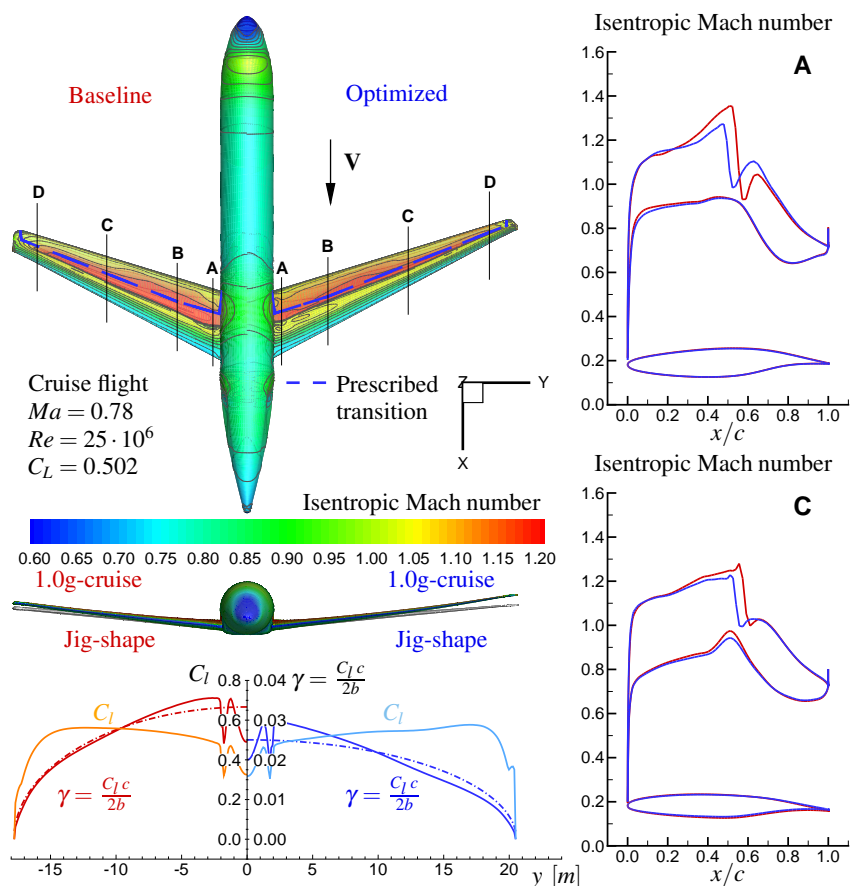

Isentropic Mach number
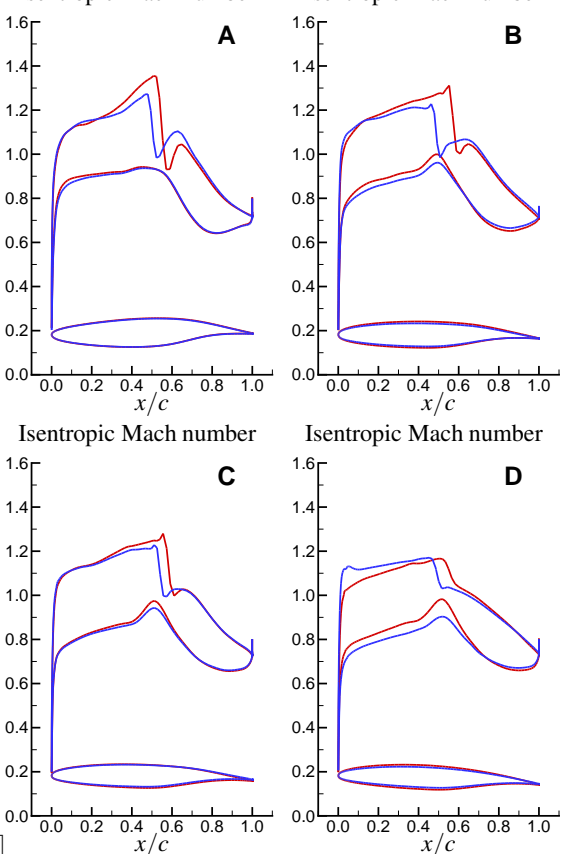

Fig. 16 Overview of wing optimization results for cruise flight.

Consequently the payload ratio $m_{P} / m_{M T O}$ increases. The main result of the wing optimization is the reduction of the fuel consumption $F C$ in the order of $9 \%$.

In Fig. 16, an overview of the wing optimization results for cruise flight condition is given. This includes the comparison of the baseline and the optimized wing in terms of isentropic Mach number distribution for the upper wing, the deformations for the $1 \mathrm{~g}$-cruise flight and the corresponding lift and lift coefficient distributions in span direction. Furthermore, the isentropic Mach number distributions and airfoil shapes are presented in four wing sections.

For each lift distribution the related elliptical lift distribution is shown by a dotdashed line as a reference. The elliptical lift distribution is the optimum for planar wings in terms of induced drag. Additionally, the prescribed laminar-turbulent transition line is shown in the isentropic Mach number distribution of Fig. 16 as a long-dashed line. The relative position in chord direction of the laminar-turbulent transition has been held constant during the optimization process. The optimized wing shows an inboard load shift and increased bending deformations in comparison to the baseline wing. In the isentropic mach number distributions of the four sections a shock strength reduction can be observed for the optimized wing. With the exception of the wing tip region the isentropic mach number distributions show accelerated flow up to $50 \%$ chord, which is necessary to limit the growth rate of Tollmien-Schlichting instabilities and maintain laminar flow. 

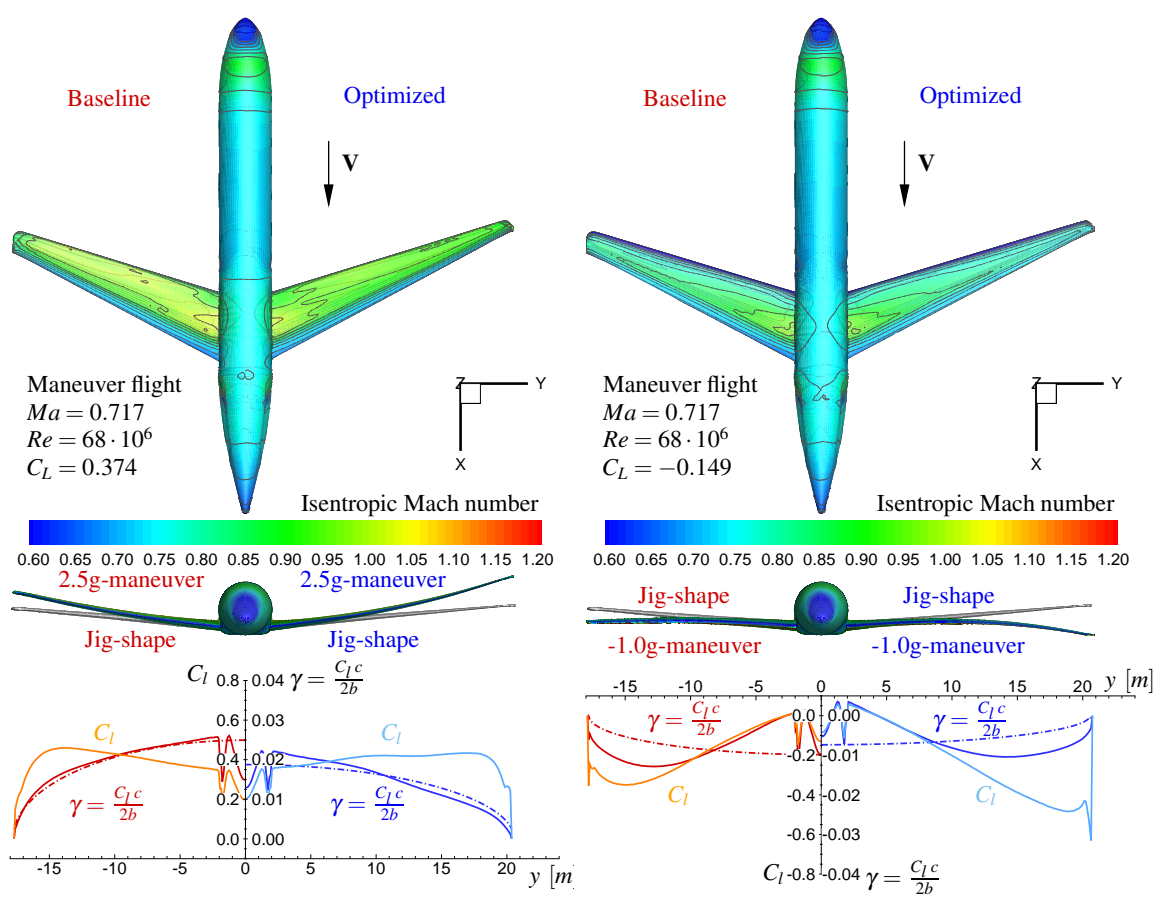

Fig. 17 Overview of wing optimization results for load case LC 2 and LC 4.

Fig. 17 shows the results for load case LC 2 and LC 4 in a similar form. An outboard load shift is observed for both wings and both maneuver flight conditions in comparison to the cruise flight. This outboard load shift of both wings can be explained with the geometrical bending-torsion coupling of the forward swept wing. Thereby, the optimized wing is more inboard loaded in comparison to the baseline wing. The reason for the reduced bending-torsion coupling of the optimized wing is the aeroelastic tailoring with the orthotropy angle of the composite material. The lift distributions of these maneuver load cases show the importance of considering the static aeroelastic effects in the loads computation for the structural wing sizing. Furthermore, an increased bending deformation of the optimized wing is observed for both maneuver flight conditions.

\section{Computing Time}

The aerostructural wing design studies and wing optimization based on high-fidelity methods require a relative high computing effort. For the aerodynamic simulations and the fluid-structure coupling the HPC-cluster $C^{2} \mathrm{~A}^{2} \mathrm{~S}^{2} \mathrm{E}$ (Center for Computer Applications in AeroSpace Science and Engineering) of the DLR Institute of Aero- 
dynamics and Flow Technology is used. In this work the aerodynamic simulations use 8 nodes of the $\mathrm{C}^{2} \mathrm{~A}^{2} \mathrm{~S}^{2} \mathrm{E}$-cluster, which equates to 192 processor cores. All other simulation programs are executed on local workstations.

\begin{tabular}{llcrr}
\hline Process & Program & $\begin{array}{c}\text { Program } \\
\text { calls }\end{array}$ & $\begin{array}{c}\text { Computing } \\
\text { time }\end{array}$ & $\begin{array}{c}\text { Computing } \\
\text { time ratio }\end{array}$ \\
\hline $\begin{array}{l}\text { CAD model update } \\
\begin{array}{l}\text { Aerodynamic grid } \\
\text { generation }\end{array}\end{array}$ & CATIA $^{\circledR}$ V5 & 1 & $1.2 \mathrm{~min}$ & $1.3 \%$ \\
$\begin{array}{l}\text { Structural model } \\
\text { generation }\end{array}$ & Pointwise & \\
$\begin{array}{l}\text { Flow simulation and } \\
\text { fluid-structure coupling }\end{array}$ & FlowSimulator (TAU-Code) & 1 & $1.8 \mathrm{~min}$ & $1.9 \%$ \\
$\begin{array}{l}\text { Structural analysis } \\
\text { and sizing }\end{array}$ & MSC Nastran & & \\
Data transfer & - & 1 & $3.3 \mathrm{~min}$ & $3.5 \%$ \\
\hline & & 7 & $53.4 \mathrm{~min}$ & $56.7 \%$ \\
\hline
\end{tabular}

Table 10 Example of the required computing time of the disciplinary simulation programs for an aerostructural wing analysis.

An example of the required computing time and the corresponding computing time ratio of the disciplinary simulation programs for an aerostructural wing analysis is given in Table 10. In this example 6 fluid-structure coupling iterations have been performed to reach the aeroelastic equilibrium of all considered load cases. With approximately $55 \%$, the aerodynamic simulation including the fluid-structure coupling requires the largest percentage of the computing time. Nevertheless, the computing time for the aerodynamic simulation is relatively short for aerostructural coupled simulations based on the Reynolds-averaged Navier-Stokes equations (RANS) due to the high degree of parallelization. The structural analysis and sizing using the finite element method (FEM) is comparatively efficient. It only needs a percentage of computing time in the order of $35 \%$.

To summarize, it can be stated that an aerostructural wing optimization with 12 design parameters requires an overall computing time in the order of 2 weeks.

Acknowledgements This work was supported by the German Federal Ministry for Economic Affairs and Energy. The authors wish to thank the Institute of Aerodynamics and Flow Technology and the Institute of Composite Structures and Adaptive Systems for providing the support of many colleagues, the IT infrastructure and the computing resources for the complex computations. 


\section{References}

[1] European Commision. European Aeronautics: A Vision for 2020. Luxembourg, Belgium: Office for Official Publications of the European Communities, 2001.

[2] European Commision. 2008 Addendum to the Strategic Research Agenda. http://www.acare4europe.com. 2008.

[3] European Commision. Flightpath 2050 Europe's Vision for Aviation. Luxembourg, Belgium: Office for Official Publications of the European Communities, 2011.

[4] N. Kroll et al. "The MEGAFLOW-Project - Numerical Flow Simulation for Aircraft”. In: Progress in Industrial Mathematics at ECMI 2004 (2005), pp. 3-33.

[5] N. Kroll et al. "Ongoing Activities in Shape Optimization Within The German Project MEGADESIGN". In: ECCOMAS 2004. 2004.

[6] N. Kroll et al. "Flow Simulation and Shape Optimization For Aircraft Design". In: Journal of Computational and Applied Mathematics 203 (Dec. 2005), pp. 397-411.

[7] N. Kroll et al. "Ongoing Activities in Flow Simulation and Shape Optimization within the German Megadesign Project". In: ICAS 2006, 25th International Congress of the Aeronautical Sciences. 2006.

[8] N. Kroll et al. MEGADESIGN and MegaOpt - German Initiatives for Aerodynamic Simulation and Optimization in Aircraft Design. Springer-Verlag Berlin Heidelberg, 2009.

[9] N. R. Gauger. "Ongoing activities in shape optimization within the German project MEGADESIGN". In: EUCCO2004, Dresden (de), 29.-31.03.2004. 2004.

[10] P. Piperni et al. "Preliminary Aerostructural Optimization of a Large Business Jet". In: Journal of Aircraft 44.5 (2007), pp. 1422-1438.

[11] K. Chiba et al. "Multidisciplinary Design Optimization and Data Mining for Transonic Regional-Jet Wing”. In: Journal of Aircraft 44.4 (2007), pp. 11001112 .

[12] A. Jameson et al. "Multi-point Aero-Structural Optimization of Wings Including Planform Variations". In: 45th Aerospace Sciences Meeting and Exhibit, Reno, Nevada, USA. AIAA 2007-764. 2007.

[13] G. K. W. Kenway and J. R. R. A. Martins. "Multipoint High-Fidelity Aerostructural Optimization of a Transport Aircraft Configuration”. In: 51 (2014). Journal of Aircraft, pp. 144-160.

[14] G. K. W. Kenway et al. "Scalable Parallel Approach for High-Fidelity SteadyState Aeroelastic Analysis and Adjoint Derivative Computations”. In: 52 (2014). AIAA Journal, pp. 935-951.

[15] R. P. Liem et al. "Multi-point, multi-mission, high-fidelity aerostructural optimization of a long-range aircraft configuration". In: 14th AIAA/ISSMO Multidisciplinary Analysis and Optimization Conference, Indianapolis, USA. Sept. 2012. 
[16] K. Horstmann and T. Streit. "Aerodynamic Wing Design for Transport Aircraft - Today: Hermann Schlichting - 100 Years”. In: ed. by R. Radespiel et al. Vol. 102. Springer-Verlag Berlin Heidelberg, 2009, pp. 130-144.

[17] G. Schrauf. "Status and perspectives of laminar flow". In: The Aeronautical Journal 109.1102 (Dec. 2005), pp. 639-644.

[18] J. E. Green. "Laminar Flow Control - Back to the Future?" In: 38th Fluid Dynamics Conference and Exhibit, Seattle, Washington, USA. AIAA 20083728. 2008.

[19] G. W. Hanks et al. Natural laminar flow analysis and trade studies. Tech. rep. NASA CR-159029. National Aeronautics and Space Administration, 1979.

[20] A. Seitz et al. "The DLR Project LamAiR: Design of a NLF Forward Swept Wing for Short and Medium Range Transport Application". In: 29th AIAA Applied Aerodynamics Conference. AIAA Conference Paper AIAA 20113526. June 2011.

[21] G. Redeker and G. Wichmann. "Forward Sweep - A Favourable Concept for a Laminar Flow Wing”. In: Journal of Aircraft 28 (1991), pp. 97-103.

[22] M. Kruse et al. "A Conceptual Study of a Transonic NLF Transport Aircraft with Forward Swept Wings". In: 30th AIAA Applied Aerodynamics Conference, New Orleans, Louisiana. AIAA Conference Paper AIAA 2012-3208. June 2012.

[23] M. H. Shirk et al. “Aeroelastic tailoring - Theory, practice, and promise". In: Journal of Aircraft 23.1 (1986), pp. 6-18.

[24] S. Dähne et al. "Steps to Feasibility for Laminar Wing Design in a Multidisciplinary Environment”. In: ICAS 2014. Sept. 2014.

[25] T. F. Wunderlich. "Multidisciplinary wing optimization of commercial aircraft with consideration of static aeroelasticity”. In: CEAS Aeronautical Journal 6.3 (2015), pp. 407-427.

[26] J. R. R. A. Martins and A. B. Lambe. "Multidisciplinary Design Optimization: A Survey of Architectures". In: AIAA Journal 51 (2013), pp. 20492075.

[27] A. B. Lambe and J. R. R. A. Martins. "Extensions to the Design Structure Matrix for the Description of Multidisciplinary Design Analysis and Optimization Processes". In: Structural and Multidisciplinary Optimization 46 (2012), pp. 273-284.

[28] R. Kamakoti and W. Shyy. "Fluid-structure interaction for aeroelastic applications”. In: Progress in Aerospace Sciences 40.8 (2005), pp. 535-558.

[29] X. B. Lam et al. "Coupled Aerostructural Design Optimization Using the Kriging Model and Integrated Multiobjective Optimization Algorithm". In: Journal of Optimization Theory and Applications 142.3 (2009), pp. 533-556.

[30] D. P. Raymer. Aircraft Design: A Conceptual Approach. Third Edition. American Institute of Aeronautics and Astronautics, 1999.

[31] C. M. Liersch and M. Hepperle. "A Unified Approach for Multidisciplinary Preliminary Aircraft Design”. In: CEAS European Air and Space Conference, Manchester, United Kingdom. 2009. 
[32] M. Galle. Ein Verfahren zur numerischen Simulation kompressibler, reibungsbehafteter Strömungen auf hybriden Netzen. Tech. rep. DLR-Forschungsbericht 99-04. Braunschweig: DLR Institut für Aerodynamik und Strömungstechnik, 1999.

[33] T. Gerhold. "Overview of the Hybrid RANS TAU-Code, In: Kroll N., Fassbender J. (Eds) MEGAFLOW - Numerical Flow Simulation Tool for Transport Aircraft Design”. In: Notes on Multidisciplinary Design 89 (2005).

[34] D. Schwamborn et al. "The DLR TAU-Code: Recent Applications in Research and Industry". In: European Conference on Computational Fluid Dynamics, ECCOMAS CFD 2006 Conference, Delft, The Netherlands. 2006.

[35] N. Kroll and J. K. Fassbender. "MEGAFLOW - Numerical Flow Simulation for Aircraft Design, Braunschweig". In: Notes on Numerical Fluid Mechanics and Multidisciplinary Design (NNFM) 89 (2002).

[36] N. Kroll et al. "MEGAFLOW - A Numerical Flow Simulation Tool For Transport Aircraft Design, Toronto, Canada". In: ICAS Congress 2002. 2002, pp. 1.105.1-1.105.20.

[37] S. R. Allmaras et al. "Modifications and Clarifications for the Implementation of the Spalart-Allmaras Turbulence Model". In: Seventh International Conference on Computational Fluid Dynamics (ICCFD7). 2012, pp. 1-11.

[38] S. Freund et al. "Parametric Model Generation and Sizing of Lightweight Structures for a Multidisciplinary Design Process". In: NAFEMS Konferenz: "Berechnung und Simulation - Anwendungen, Entwicklungen, Trends. May 2014.

[39] M.-H.-1.-3. Military. Composite Materials Handbook, Polymer Matrix Composites: Materials Usage, Design, and Analysis. Vol. 3 of 5. US Department of Defense, June 2002.

[40] HyperSizer Documentation. Collier Research Corporation. Newport News, 2015.

[41] H. Barnewitz and B. Stickan. "Improved Mesh Deformation". In: Notes on Numerical Fluid Mechanics and Multidisciplinary Design. Ed. by B. Eisfeld et al. Vol. 122. 2013, pp. 219-243.

[42] M. Meinel and G. O. Einarsson. "The FlowSimulator framework for massively parallel CFD applications". In: PARA 2010 conference, 6-9 June, Reykjavik, Iceland. 2010.

[43] L. Reimer et al. "Multidisciplinary Analysis Workflow with the FlowSimulator". In: Proceedings of the Onera Scientific Day 2012-CFD Workflow: Mesh, Solving, Visualizing, ... Ed. by C. Benoit et al. Vol. 19. Amphithéâtre Becquerel, École Polytechnique, Palaiseau, 2012, pp. 23-30.

[44] G. Wilke. "Multi-Objective Optimizations in Rotor Aerodynamics using Variable Fidelity Simulations". In: 39th European Rotorcraft Forum. Sept. 2013, pp. 1-13.

[45] D. R. Jones et al. "Efficient Global Optimization of Expensive Black-Box Functions". In: Journal of Global Optimization 13 (1998), pp. 455-492.

[46] A. Forrester et al. Engineering Design via Surrogate Modelling: A Practical Guide. Wiley, 2008. 
[47] D. G. Krige. "A Statistical Approach to Some Basic Mine Valuation Problems on the Witwatersrand". In: Journal of the Chemical, Metallurgical and Mining Society of South Africa 52.6 (Dec. 1951), pp. 119-139.

[48] M. Kintscher et al. "Design of a smart leading edge device for low speed wind tunnel tests in the European project SADE". In: International Journal of Structural Integrity 2.4 (2011), pp. 383-405.

[49] G. K. W. Kenway et al. "Aerostructural optimization of the Common Research Model configuration". In: 15th AIAA/ISSMO Multidisciplinary Analysis and Optimization Conference, Georgia, USA. June 2014.

[50] T. F. Wunderlich. "Multidisziplinärer Entwurf und Optimierung von Flügeln für Verkehrsflugzeuge”. In: Deutscher Luft- und Raumfahrtkongress, Aachen. DGLR-Tagungsband - Ausgewählte Manuskripte DLRK2009-1181. Sept. 2009. 